\title{
COMPOSIÇÃO E DISTRIBUIÇÃO DOS MACROINVERTEBRADOS EM DIFERENTES SUBSTRATOS DE FUNDO DE UM RIACHO NO MUNICÍPIO DE ITATINGA, SÃO PAULO, BRASIL
}

\author{
Regina Mayumi Kikuchi(1) \& Virgínia Sanches Uieda ${ }^{(2)}$
}

\begin{abstract}
Composition and distribution of Macroinvertebrates in different types of substrate of a stream in the Municipal District of Itatinga, São Paulo, Brazil - The distribution pattern of aquatic organisms results from the interaction of the habit, the physical conditions of the habitat (substrate, flow, turbulence) and the food availability. The purpose of this study is to know the composition and to understand the pattern of distribution of the animal community of a tropical stream. The collections were accomplished in a tributary of the Basin of Paranapanema, located in the municipal district of Itatinga, São Paulo. When analyzed the occurrence in different types of substrate - vegetal, rocky and sandy - we found a larger density in the rocky substrate and larger diversity in the vegetal substrate. In the three substrata, the invertebrates of the class Insecta, and mainly the order Diptera, prevailed in abundance and diversity of species. Of this order, in the vegetal and rocky substrate prevailed the families Chironomidae and Simuliidae and in the sediment, the family Chironomidae. Between the Chironomidae was found several genera, with many individuals, of the subfamily Ortocladiinae.
\end{abstract}

(1) Programa de Pós-graduação em Ecologia e Recursos Naturais, Universidade Federal de São Carlos, Caixa postal 676, Rodovia Washington Luis, Km 235, CEP: 13565-905, São Carlos, SP, Brasil. E-mail: rmkikuchi@yahoo.com.br; (2) Universidade Estadual Paulista "Júlio de Mesquita Filho", Instituto de Biociências, Departamento Zoologia, Distrito de Rubião Júnior s/n, Caixa Postal no 510, CEP: 18.618-000 Botucatu, São Paulo, Brasil. Com auxílio da Fapesp e CNPq 
Key words: Macroinvertebrates, lotic environment, distribution, substrate, ordination

\section{Resumo}

O padrão de distribuição de organismos aquáticos é resultado da interação entre o hábito, as condições físicas, que compreendem o hábitat (substrato, fluxo, turbulência) e a disponibilidade alimentar. O presente trabalho teve como objetivo conhecer a composição e compreender o padrão de distribuição das comunidades animais de um riacho tropical. As coletas foram realizadas em um afluente da Bacia do Paranapanema, localizado no município de Itatinga, São Paulo. Quando analisada a ocorrência em diferentes tipos de substrato de fundo - vegetal, rochoso e arenoso encontramos uma maior densidade no substrato rochoso e maior riqueza no substrato vegetal. Nos três substratos, os invertebrados da classe Insecta, e principalmente a ordem Diptera, predominaram em abundância e riqueza de espécies. Desta ordem, nos substratos vegetal e rochoso predominaram as famílias Chironomidae e Simuliidae e no sedimento, a família Chironomidae. Dentre os quironomídeos foram encontrados diversos gêneros, com muitos indivíduos, da subfamília Ortocladiinae.

Palavras-chave: Macroinvertebrados, ambiente lótico, distribuição, substrato, ordenação

\section{Introdução}

O padrão de distribuição de organismos aquáticos é resultado da interação entre o hábito, as condições físicas, que compreendem o hábitat (substrato, fluxo, turbulência) e a disponibilidade alimentar (Resh \& Rosenberg, 1984; Merritt \& Cummins, 1984).

O substrato é um aspecto complexo do ambiente físico (Allan, 1995), e pode atuar diretamente nos insetos como um meio de sua existência, e indiretamente como o principal modificador de seu ambiente (Resh \& Rosenberg, 1984).

Segundo Resh \& Rosenberg (1984), o substrato é o meio físico sobre o qual os invertebrados aquáticos se movem, descansam, procuram alimento, 
encontram abrigo (dos predadores, da corrente ou de alterações ambientais), constróem casa e depositam ovos. O substrato é constituído por vários tipos de materiais orgânicos e inorgânicos, suficientemente estáveis para que os insetos possam rastejar, se agarrar, ou se esconder (Resh \& Rosenberg, 1984). Os substratos orgânicos podem ser de origem alóctone, constituídos por folhas, galhos ou capim, e de origem autóctone, quando apresentam filamentos de algas, musgos, hidrófitas vasculares, ou ainda insetos aquáticos. Os substratos inorgânicos geralmente são compostos por granitos ou então materiais sedimentares, variando em tamanho, desde o microscópico silte até os grandes seixos (Resh \& Rosenberg, 1984). Em geral, pedras grandes constituem um substrato mais complexo, com uma fauna de invertebrados mais diversa. Agregação de folhas no fundo de riachos geralmente sustenta uma grande diversidade e abundância de invertebrados (Allan, 1995). A areia é um hábitat relativamente pobre, com poucos espécimes de poucas espécies (Hynes, 1970), possivelmente por ser um ambiente mais instável (Allan, 1995).

Em geral, a diversidade e abundância aumentam com a estabilidade do substrato e a presença de detritos orgânicos (Allan, 1995).

O substrato raramente exerce sua influência em isolado (Resh \& Rosenberg, 1984), como veremos neste trabalho quando coletamos organismos em tipos diferentes de substrato de fundo, em distintas áreas (área fechada e aberta), trechos (corredeira e poção) e com uma variação estacional (período seco e chuvoso).

O projeto geral teve como objetivo conhecer a composição e compreender o padrão de distribuição das comunidades animais de um riacho tropical. Uma análise qualitativa (presença/ausência) da comunidade de macroinvertebrados foi realizada neste mesmo trecho, sendo os resultados apresentados em Kikuchi \& Uieda (1998). Dentre os fatores analisados, este trabalho trata especificamente da ocorrência (análise quantitativa) de macroinvertebrados encontrados em diferentes substratos de fundo do riacho - vegetal, rochoso e arenoso, e a variação da comunidade desses substratos por área, trecho e período.

\section{Material e Métodos}

\section{Área de Estudo}

O trabalho foi realizado em um afluente da Bacia do Paranapanema, Município de Itatinga, São Paulo. Do afluente, chamado Córrego Itaúna 
(um riacho de $3^{a}$ ordem), foram escolhidas duas áreas, a Área Fechada e a Aberta. A primeira área, localizada a montante, é margeada por uma mata galeria, formando um dossel fechado sobre o rio; a segunda área, localizada a jusante, apresenta somente vegetação marginal arbustiva, pendente sobre a água, com incidência de luz sobre o leito.

Nas duas áreas, são observados trechos de poções e corredeiras intercalados. Os poções, com leito rochoso coberto de areia, são mais fundos, de menor extensão e menor velocidade da corrente do que as corredeiras. Estas são constituídas de fundo pedregoso, com substrato variando desde matacões a seixos.

De acordo com índices pluviométricos do município de Itatinga, para o período de coleta, foi delimitada a estação chuvosa (mais quente) dos meses de novembro a abril e a estação seca (mais fria) de maio a outubro.

\section{Coleta e Identificação}

As coletas foram realizadas bimestralmente, no período de outubro de 1990 a agosto de 1991.

Amostras de substrato vegetal (folhas e galhos) foram coletadas em poções e corredeiras; de substrato rochoso, em corredeiras, e de sedimento, em poções. As folhas e galhos, contidos dentro de uma área delimitada por um quadrante $(30 \mathrm{~cm} \times 30 \mathrm{~cm})$, tendo uma profundidade máxima de $10 \mathrm{~cm}$, foram recolhidos e lavados em um balde com água do próprio ambiente (semelhante a técnica dos quadrados de PAYNE, 1986). O material coletado foi fixado em formaldeído a $4 \%$. O mesmo procedimento foi usado em relação ao substrato rochoso. O sedimento foi coletado manualmente e acondicionado em potes plásticos de volume conhecido. De cada um dos três substratos, foram coletadas 3 amostras por mês. Um total de seis coletas durante 0 ano foram realizadas, a intervalos de dois meses cada, perfazendo 18 amostras por substrato. O substrato vegetal foi coletado tanto em poções como em corredeiras e acondicionado separadamente.

Para a identificação dos invertebrados aquáticos foram utilizadas as chaves de: Borror \& Delong (1969), Mason (1973), Oliver et al. (1978), Pennak (1978), Stehr (1987), Merritt \& Cummins (1984), Pérez (1988), Carvalho (1989), Trivinho-Strixino \& Strixino (1991; 1995), Belle (1992), Epler (1992) e Lopretto \& Tell (1995). 


\section{Análise dos dados}

Com os dados de número de indivíduos de macroinvertebrados em diferentes tipos de substrato de fundo, foi calculada a abundância, densidade relativa e riqueza de espécies. Com os dados de densidade ( $n$ de invivíduos $/ \mathrm{m}^{3}$ ) foi realizada uma análise de variância e de ordenação, conforme descrição abaixo.

Abundância: número de indivíduos amostrados em uma dada área.

Densidade relativa: abundância (número total de indivíduos de uma espécie) expressa como uma proporção ou porcentagem do número total de indivíduos de todas as espécies. Esta medida foi utilizada para determinar os grupos predominantes, em cada uma das situações analisadas.

Densidade: número de indivíduos expresso por unidade de volume $\left(\mathrm{m}^{3}\right)$. Esta medida foi utilizada na comparação entre os três substratos da coleta específica (vegetal, rochoso e sedimento), por permitir uma padronização quanto ao volume de amostragem. Para os substratos vegetal e rochoso, o volume foi determinado multiplicando a área do quadrante $\left(900 \mathrm{~cm}^{2}\right)$ por uma profundidade de $10 \mathrm{~cm}$, totalizando $9000 \mathrm{~cm}^{3}$. Para o sedimento, o volume foi o do frasco utilizado na coleta $\left(785 \mathrm{~cm}^{3}\right)$.

Ordenação: Análise de Correspondência "Detrended" (DCA):

As técnicas de ordenação arranjam as unidades amostrais ao longo de eixos criados a partir dos dados de composição de espécies (Ter Braak, 1995). O resultado de uma ordenação é um diagrama bidimensional (com dois eixos), no qual as unidades amostrais são representadas por pontos. O objetivo da ordenação é arranjar os pontos de maneira que os mais próximos correspondam a unidades amostrais semelhantes na composição de espécies. A análise de DCA é uma técnica de ordenação que assume que as respostas das espécies às variáveis ambientais são unimodais ao invés de lineares. Ou seja, para esta análise as espécies têm um ótimo, um valor da variável ambiental onde a espécie tem maior abundância ou maior probabilidade de ocorrência. A partir deste ponto a abundância decresce em ambos os sentidos. Com o aumento e com diminuição do valor da variável ambiental, esta diminuição assume a forma de uma curva Gaussiana (Ter Braak \& Prentice, 1988). Os táxons raros (aparecimento em menos de cinco unidades amostrais) foram excluídos da análise a fim de reduzir 
sua influência sobre a ordenação (Ter Braak, 1995). Após a realização da ordenação foi executada uma análise de variância a fim de testar a influência dos fatores ambientais estudados na composição de espécies (Reid et al., 1995).

\section{Resultados}

\section{Invertebrados - substrato vegetal}

Os macroinvertebrados encontrados no substrato vegetal, coletado no Córrego Itaúna, pertencem a 5 filos, destacando-se o filo Arthropoda. Deste filo, sobressaiu-se a classe Insecta com 9 ordens, com o predomínio da ordem Diptera com 9 famílias (Tab. I).

Quando calculada a densidade relativa (Fig. 1), este predomínio é confirmado, pois a ordem Diptera representa $82 \%$ dos indivíduos coletados. Apesar de ocorrer em porcentagem bem inferior a Diptera, as ordens Plecoptera $(7,4 \%)$, Ephemeroptera $(4,1 \%)$, Coleoptera $(3,2 \%)$ e Trichoptera $(1,9 \%)$ se sobressaíram também na análise por período (Fig. 1), área e trecho (Fig. 2).

A densidade relativa dos invertebrados associados ao substrato vegetal foi maior no período seco, na Área aberta e no trecho de corredeira (Tab. II). As famílias Simuliidae e Chironomidae (ordem Diptera), totalizaram $80 \%$ de todos os invertebrados coletados neste tipo de substrato. Os quironomídeos sobressaíram-se no período seco e em poções, os simulídeos no período chuvoso e em corredeiras. Estas duas famílias predominaram em igual proporção nas áreas fechada e aberta. Apesar de ocorrência menor em relação aos dípteros, outros grupos também foram importantes, como Gripopterygidae (Plecoptera), Elmidae (Coleoptera), Leptohyphidae (Ephemeroptera) e Hydropsychidae (Trichoptera).

A análise de variância, aplicada para os dados referentes à família Chironomidae e ao total da comunidade, mostrou que as diferenças na abundância entre períodos, áreas e trechos eram significativas (Tab. III). Esta análise comprovou a predominância de Chironomidade no período seco e a predominância de invertebrados (total da comunidade) na Área aberta e em trechos de corredeira. 


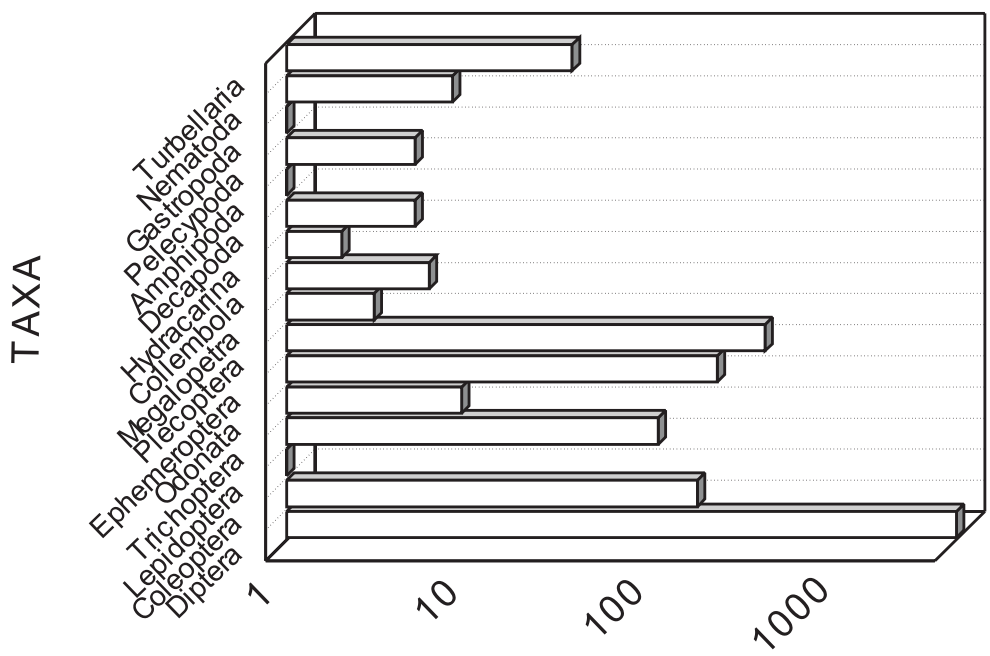

A

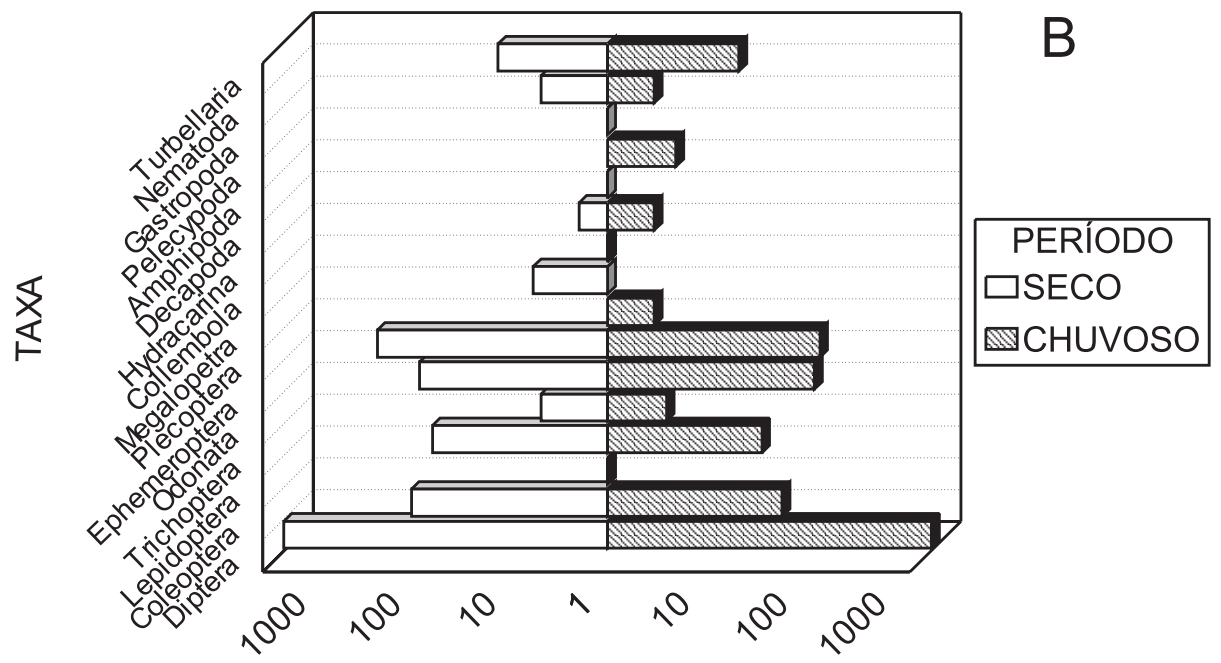

Figura 1: Densidade relativa (log 10) de invertebrados encontrados no substrato vegetal, coletado no Córrego Itaúna, no ano (A) e em cada período (B). 

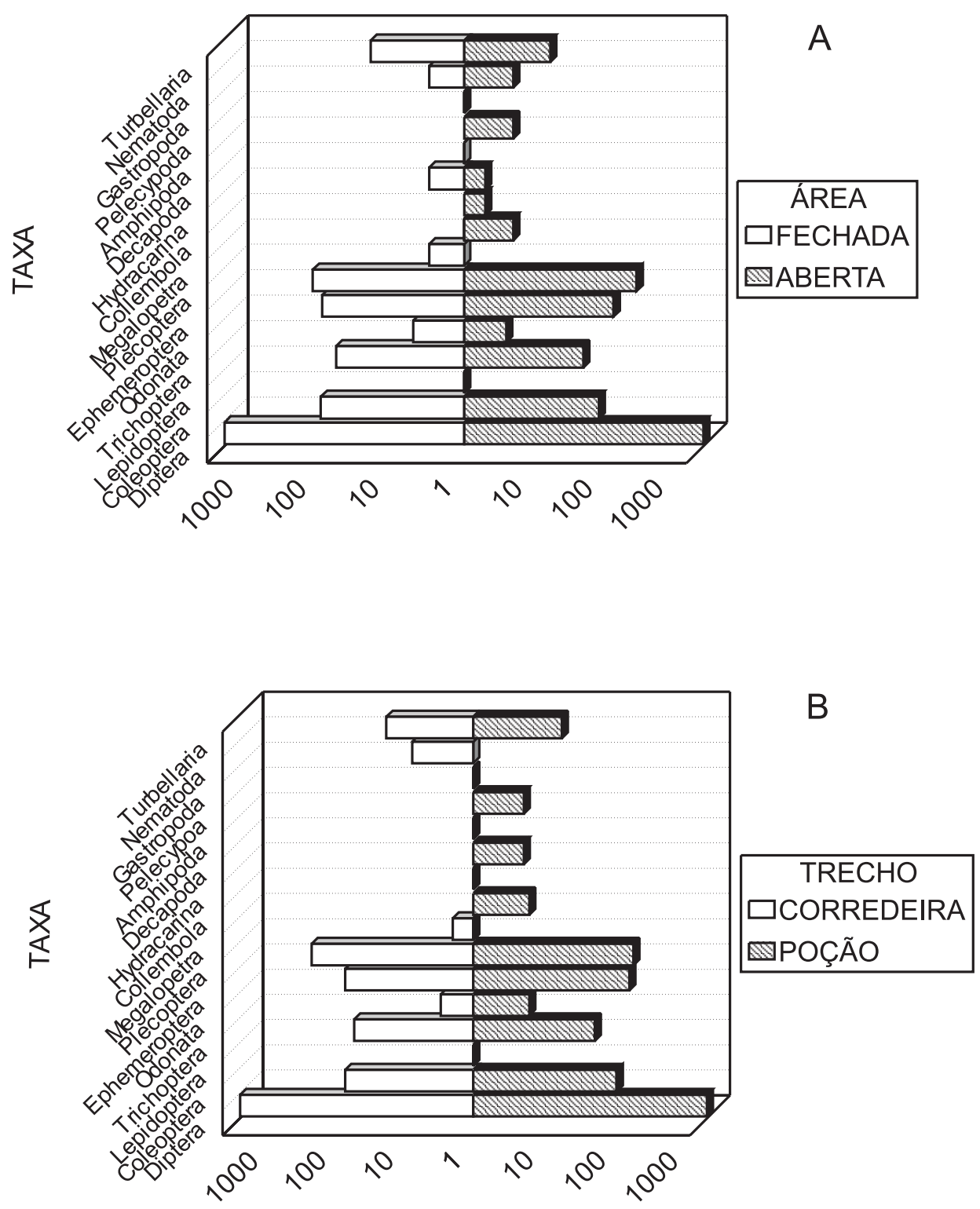

Figura 2: Densidade relativa (log 10) de invertebrados encontrados no substrato vegetal, coletado no Córrego Itaúna, em cada área $(A)$ e trecho $(B)$. 


\section{Invertebrados - substrato rochoso}

No substrato rochoso, foram encontrados organismos pertencentes a 5 filos, com predomínio do filo Arthropoda, sendo a classe Insecta representada por 7 ordens. As ordens com maior número de famílias foram Trichoptera e Diptera, ambas representadas por 5 famílias (Tab. IV).

Neste substrato, a ordem Diptera compreendeu $89 \%$ dos macroinvertebrados coletados, sendo seguida, em porcentagem menor, por Ephemeroptera $(5,3 \%)$ e Trichoptera $(3,5 \%)$. Estes grupos apresentaram um predomínio, na análise da densidade relativa por período e área (Fig. 3).

Os macroinvertebrados do substrato rochoso apresentaram uma maior densidade relativa no período seco e na Área aberta (Tab. V). As famílias Chironomidae e Simuliidae (ordem Diptera) foram responsáveis por $89 \%$ de todos os macroinvertebrados coletados neste substrato, sendo predominantes no período seco e na Área fechada. Em menor porcentagem, mas também importantes, foram encontrados representantes de Baetidae e Leptohyphidae (Ephemeroptera), Hydroptilidae e Hydropsychidae (Trichoptera).

Para verificar se as diferenças na abundância entre período e área eram siginificativas, a análise de variância foi aplicada nos dados referentes às famílias Chironomidae, Simuliidae e para o total da comunidade. Os resultados desta análise (Tab. VI) comprovaram a predominância de Chironomidae, Simuliidae e de toda a comunidade no período seco. Porém, não houve diferenças significativas entre as áreas.

\section{Invertebrados - sedimento}

No sedimento, foram encontrados invertebrados pertencentes a cinco filos, com predomínio do filo Arthropoda. Neste, a classe Insecta foi predominante, com maior número de organismos em 4 ordens. A ordem Diptera apresentou maior riqueza de espécies, sendo representada por 3 famílias (Tab. VII).

Quanto à densidade relativa, houve predomínio da ordem Diptera $(46,4 \%)$ e de um molusco da classe Pelecypoda $(42,4 \%)$, sendo seguidos, em menor porcentagem, por Odonata e Nematoda (4,9\%). A importância destes grupos foi mantida, tanto por período como por área (Fig. 4). 


\section{Tabela I}

Macroinvertebrados encontrados no substrato vegetal, coletado no Córrego Itaúna, no período de outubro/1990 a agosto/1991.

Filo Platyhelminthes

Filo Nematoda

Filo Annelida

Classe Oligochaeta

Filo Mollusca

Família Ancylidae

Família Sphaeriidae

Pisidium sp.

Filo Arthropoda

Classe Crustacea

Ordem Amphipoda

Hyalella azteca

Ordem Decapoda

Família Porcelanidae Aegla sp.

Família Trichodactilidae

Classe Arachnida

Ordem Acarina (Hydracarina)

Classe Insecta

Ordem Collembola

Família Isotomidae

Semicerura sp.

Ordem Megaloptera

Família Corydalidae

Corydalus sp.

Ordem Plecoptera

Família Gripopterygidae

Gripopterix sp.

Paragripopterix sp.

Tupiperla sp.

Família Perlidae

Anacroneuria sp.
Ordem Ephemeroptera

Família Leptohyphidae

Leptohyphes sp.

Famíla Leptophlebiidae

Família Baetidae

Baetis sp.

Baetodes sp.

Ordem Odonata

Subordem Zygoptera

Família Calopterygidae

Hetaerina sp.

Família Coenagrionidae

Subordem Anisoptera

Família Aeshnidae

Ordem Trichoptera

Família Hydropsychidae

Smicridea sp.

Leptonema sp.

Família Hydroptilidae Neotrichia sp.

Família Leptoceridae Nectopsyche sp.

Família Philopotamidae Chimarra sp.

Família Calamoceratidae

Phylloicus sp.

Ordem Lepidoptera

Família Tortricidae

Archips sp.

Ordem Coleoptera

Família Gyrinidae

Gyretes sp.

Família Elmidae

Heterelmis sp.

Phanocerus sp.

Família Limnichidae

Lutrochus sp. 


\author{
Ordem Diptera \\ Família Ceratopogonidae \\ Família Chironomidae \\ Ablabesmyia sp. \\ Fittkauimyia sp. \\ Labrundinia sp. \\ Larsia sp. \\ Pentaneura sp. \\ Corynoneura sp. \\ Thienemanniella sp. \\ Cricotopus sp1. \\ Crico./Orthocladius sp. \\ Limnophyes sp. \\ Metriocnemus sp. \\ Nanocladius sp. \\ Rheocricotopus sp. \\ Parametriocnemus sp. \\ Orthocladiinae (tipo1) \\ Orthocladiinae (tipo2) \\ Orthocladiinae (tipo3) \\ Orthocladiinae (tipo4)
}

Família Staphylinidae

Stenus sp.

Família Dytiscidae

Chironomus sp.

Cryptochironomus sp.

Phaenopsectrasp.

Polypedilum sp.

Stenochironomus sp.

Xestochironomus sp.

Nimbocera paulensis

Tanytarsus sp.

Rheotanytarsus sp.

Família Empididae

Hemerodromia sp.

Chelifera sp.

Família Ephydridae

Família Muscidae

Famíla Psychodidae

Maruina sp.

Pericoma sp.

Família Scatophagidae

Família Sciomyzidae

Família Simuliidae

A densidade relativa dos macroinvertebrados presentes no sedimento (Tabela VIII) foi maior no período seco e na Área aberta. As famílias Chironomidae (ordem Diptera) e Sphaeriidae (Filo Mollusca) predominaram, sendo seguidas, em menor porcentagem, por Gomphidae (Odonata) e pelo Filo Nematoda. A família Chironomidae apresentou predomínio no período seco e na Área aberta, enquanto o filo Mollusca (Sphaeriidae), no período chuvoso e Área fechada (Tab. VIII). Porém, a aplicação da análise de variância para os dados de densidade não resultou em diferenças significativas para nenhum dos fatores analisados (período e área).

\section{Comparação entre substratos}

A densidade de macroinvertebrados nos substratos vegetal, rochoso e sedimento foi maior no período seco, Área aberta e em trecho de corredeira (este último fator analisado somente para o substrato vegetal). 
Tabela II

\section{Abundância (N) e densidade relativa (\%) dos invertebrados do substrato vegetal, coletado no Córrego Itaúna, por período.}

\begin{tabular}{|c|c|c|c|c|c|c|c|c|c|c|c|c|c|c|}
\hline \multirow[b]{3}{*}{ TAXA } & \multicolumn{4}{|c|}{ PERIODO } & \multicolumn{4}{|c|}{ AREA } & \multicolumn{4}{|c|}{ TRECHO } & \multirow{2}{*}{\multicolumn{2}{|c|}{ TOTAL }} \\
\hline & \multicolumn{2}{|c|}{$\mathrm{Sec}$} & \multicolumn{2}{|c|}{ Chu } & \multicolumn{2}{|c|}{ Af } & \multicolumn{2}{|c|}{$\mathrm{Aa}$} & \multicolumn{2}{|c|}{ Cor } & \multicolumn{2}{|c|}{ Poç } & & \\
\hline & $\mathrm{N}$ & $\%$ & $\mathrm{~N}$ & $\%$ & $\mathrm{~N}$ & $\%$ & $\mathrm{~N}$ & $\%$ & $\mathrm{~N}$ & $\%$ & $\mathrm{~N}$ & $\%$ & $\mathrm{~N}$ & $\%$ \\
\hline PLATYHELMINTHES & & & & & & & & & & & & & & \\
\hline Turbellaria & 14 & 0,47 & 22 & 0,89 & 19 & 0,83 & 17 & 0,53 & 19 & 0,60 & 17 & 0,75 & 36 & 0,66 \\
\hline $\begin{array}{l}\text { NEMATODA } \\
\text { MOLLUSCA }\end{array}$ & 5 & 0,17 & 3 & 0,12 & 3 & 0,13 & 5 & 0,16 & 8 & 0,25 & 0 & 0,00 & 8 & 0,15 \\
\hline Ancylidae & 1 & 0,03 & 0 & 0,00 & 0 & 0,00 & 1 & 0,03 & 0 & 0,00 & 1 & 0,04 & 1 & 0,02 \\
\hline $\begin{array}{l}\text { Sphaeriidae } \\
\text { ARTHROPODA } \\
\text { Crustacea } \\
\text { Amphipoda }\end{array}$ & 0 & 0,00 & 5 & 0,20 & 0 & 0,00 & 5 & 0,16 & 0 & 0,00 & 5 & 0,22 & 5 & 0,09 \\
\hline $\begin{array}{l}\text { Talitridae } \\
\text { Decapoda }\end{array}$ & 1 & 0,03 & 0 & 0,00 & 1 & 0,04 & 0 & 0,00 & 0 & 0,00 & 1 & 0,04 & 1 & 0,02 \\
\hline Aeglidae & 2 & 0,07 & 2 & 0,08 & 3 & 0,13 & 1 & 0,03 & 0 & 0,00 & 4 & 0,18 & 4 & 0,07 \\
\hline $\begin{array}{l}\text { Trichodactilidae } \\
\text { Arachnida }\end{array}$ & 0 & 0,00 & 1 & 0,04 & 0 & 0,00 & 1 & 0,03 & 0 & 0,00 & 1 & 0,04 & 1 & 0,02 \\
\hline $\begin{array}{l}\text { Hydracarina } \\
\text { Insecta }\end{array}$ & 1 & 0,03 & 1 & 0,04 & 0 & 0,00 & 2 & 0,06 & 1 & 0,03 & 1 & 0,04 & 2 & 0,04 \\
\hline Collembola & & & & & & & & & & & & & & \\
\hline $\begin{array}{l}\text { Isotomidae } \\
\text { Megaloptera }\end{array}$ & 6 & 0,20 & 0 & 0,00 & 1 & 0,04 & 5 & 0,16 & 0 & 0,00 & 6 & 0,26 & 6 & 0,11 \\
\hline $\begin{array}{l}\text { Corydalidae } \\
\text { Plecoptera }\end{array}$ & 0 & 0,00 & 3 & 0,12 & 3 & 0,13 & 0 & 0,00 & 2 & 0,06 & 1 & 0,04 & 3 & 0,05 \\
\hline Gripopterygidae & 252 & 8,47 & 149 & 6,00 & 114 & 5,01 & 287 & 9,02 & 233 & 7,32 & 168 & 7,39 & 401 & 7,35 \\
\hline Perlidae & 4 & 0,13 & 0 & 0,00 & 3 & 0,13 & 1 & 0,03 & 4 & 0,13 & 0 & 0,00 & 4 & 0,07 \\
\hline Ephemeroptera & 19 & 0,64 & 20 & 0,81 & 19 & 0,83 & 20 & 0,63 & 18 & 0,57 & 21 & 0,92 & 39 & 0,71 \\
\hline Leptohyphidae & 60 & 2,02 & 76 & 3,06 & 55 & 2,42 & 81 & 2,55 & 38 & 1,19 & 98 & 4,31 & 136 & 2,49 \\
\hline Leptophlebiidae & 1 & 0,03 & 4 & 0,16 & 0 & 0,00 & 5 & 0,16 & 1 & 0,03 & 4 & 0,18 & 5 & 0,09 \\
\hline $\begin{array}{l}\text { Baetidae } \\
\text { Odonata }\end{array}$ & 12 & 0,40 & 31 & 1,25 & 14 & 0,62 & 29 & 0,91 & 19 & 0,60 & 24 & 1,06 & 43 & 0,79 \\
\hline Zygoptera & 3 & 0,10 & 1 & 0,04 & 1 & 0,04 & 3 & 0,09 & 3 & 0,09 & 1 & 0,04 & 4 & 0,07 \\
\hline Anisoptera & 0 & 0,00 & 1 & 0,04 & 0 & 0,00 & 1 & 0,03 & 0 & 0,00 & 1 & 0,04 & 1 & 0,02 \\
\hline Calopterygidae & 1 & 0,03 & 0 & 0,00 & 1 & 0,04 & 0 & 0,00 & 0 & 0,00 & 1 & 0,04 & 1 & 0,02 \\
\hline Aeshnidae & 1 & 0,03 & 1 & 0,04 & 2 & 0,09 & 0 & 0,00 & 0 & 0,00 & 2 & 0,09 & 2 & 0,04 \\
\hline $\begin{array}{l}\text { Coenagrionidae } \\
\text { Trichoptera }\end{array}$ & 0 & 0,00 & 1 & 0,04 & 1 & 0,04 & 0 & 0,00 & 0 & 0,00 & 1 & 0,04 & 1 & 0,02 \\
\hline Hydropsychidae & 58 & 1,95 & 34 & 1,37 & 46 & 2,02 & 46 & 1,45 & 53 & 1,67 & 39 & 1,72 & 92 & 1,69 \\
\hline Hydroptilidae & 0 & 0,00 & 1 & 0,04 & 1 & 0,04 & 0 & 0,00 & 1 & 0,03 & 0 & 0,00 & 1 & 0,02 \\
\hline Leptoceridae & 4 & 0,13 & 2 & 0,08 & 5 & 0,22 & 1 & 0,03 & 3 & 0,09 & 3 & 0,13 & 6 & 0,11 \\
\hline Philopotamidae & 3 & 0,10 & 0 & 0,00 & 3 & 0,13 & 0 & 0,00 & 0 & 0,00 & 3 & 0,13 & 3 & 0,05 \\
\hline $\begin{array}{l}\text { Calamoceratidae } \\
\text { Lepidoptera }\end{array}$ & 3 & 0,10 & 1 & 0,04 & 1 & 0,04 & 3 & 0,09 & 0 & 0,00 & 4 & 0,18 & 4 & 0,07 \\
\hline $\begin{array}{l}\text { Tortricidae } \\
\text { Coleoptera }\end{array}$ & 0 & 0,00 & 1 & 0,04 & 0 & 0,00 & 1 & 0,03 & 0 & 0,00 & 1 & 0,04 & 1 & 0,02 \\
\hline Gyrinidae & 3 & 0,10 & 1 & 0,04 & 2 & 0,09 & 2 & 0,06 & 1 & 0,03 & 3 & 0,13 & 4 & 0,07 \\
\hline Elmidae & 106 & 3,56 & 59 & 2,38 & 88 & 3,87 & 77 & 2,42 & 74 & 2,32 & 91 & 4,00 & 165 & 3,02 \\
\hline Limnichidae & 3 & 0,10 & 0 & 0,00 & 0 & 0,00 & 3 & 0,09 & 1 & 0,03 & 2 & 0,09 & 3 & 0,05 \\
\hline Staphylinidae & 1 & 0,03 & 0 & 0,00 & 0 & 0,00 & 1 & 0,03 & 0 & 0,00 & 1 & 0,04 & 1 & 0,02 \\
\hline $\begin{array}{l}\text { Dytiscidae } \\
\text { Diptera }\end{array}$ & 0 & 0,00 & 1 & 0,04 & 1 & 0,04 & 0 & 0,00 & 0 & 0,00 & 1 & 0,04 & 1 & 0,02 \\
\hline Ceratopogonidae & 2 & 0,07 & 1 & 0,04 & 1 & 0,04 & 2 & 0,06 & 2 & 0,06 & 1 & 0,04 & 3 & 0,05 \\
\hline Chironomidae & 1515 & 50,92 & 657 & 26,47 & 934 & 41,04 & 1238 & 38,92 & 800 & 25,13 & 1372 & 60,33 & 2172 & 39,80 \\
\hline Empididae & 36 & 1,21 & 17 & 0,68 & 16 & 0,70 & 37 & 1,16 & 30 & 0,94 & 23 & 1,01 & 53 & 0,97 \\
\hline Ephydridae & 1 & 0,03 & 1 & 0,04 & 1 & 0,04 & 1 & 0,03 & 1 & 0,03 & 1 & 0,04 & 2 & 0,04 \\
\hline Muscidae & 1 & 0,03 & 0 & 0,00 & 0 & 0,00 & 1 & 0,03 & 0 & 0,00 & 1 & 0,04 & 1 & 0,02 \\
\hline Psychodidae & 1 & 0,03 & 2 & 0,08 & 0 & 0,00 & 3 & 0,09 & 0 & 0,00 & 3 & 0,13 & 3 & 0,05 \\
\hline Scatophagidae & 6 & 0,20 & 0 & 0,00 & 0 & 0,00 & 6 & 0,19 & 6 & 0,19 & 0 & 0,00 & 6 & 0,11 \\
\hline Sciomyziidae & 1 & 0,03 & 0 & 0,00 & 0 & 0,00 & 1 & 0,03 & 1 & 0,03 & 0 & 0,00 & 1 & 0,02 \\
\hline Simuliidae & 848 & 28,50 & 1383 & 55,72 & 937 & 41,17 & 1294 & 40,68 & 1864 & 58,56 & 367 & 16,14 & 2231 & 40,88 \\
\hline SUBTOTAL & 2975 & & 2482 & & 2276 & & 3181 & & 3183 & & 2274 & & 5457 & \\
\hline & & 54,52 & & 45,48 & & 41,71 & & 58,29 & & 58,33 & & 41,67 & & \\
\hline
\end{tabular}

Sec: seco, Chu: chuvoso), Af: área fechada, Aa: área aberta); Cor: corredeira; Poç:poção. 


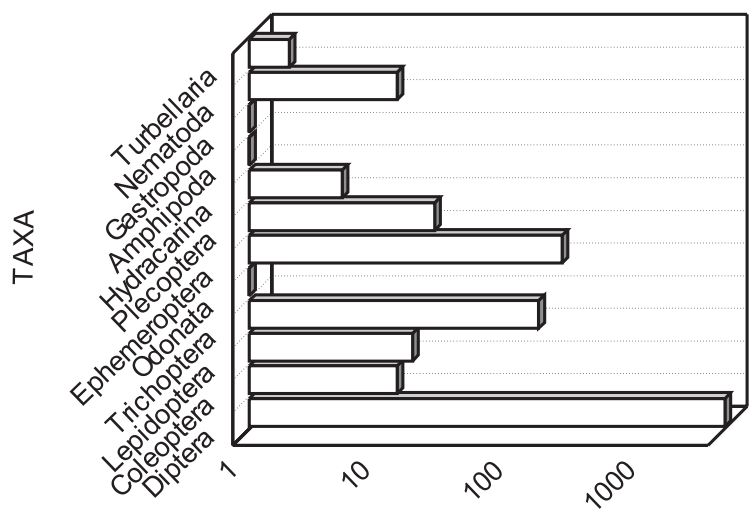

A

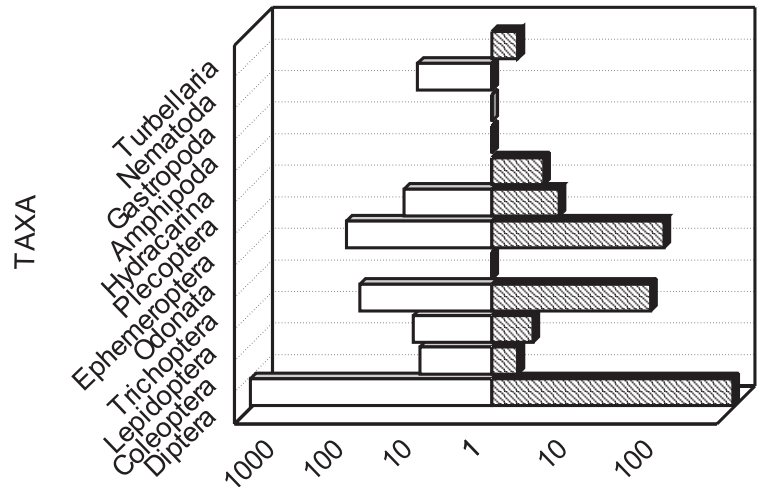

B

\section{PERIODO $\square$ पSCO

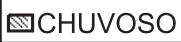

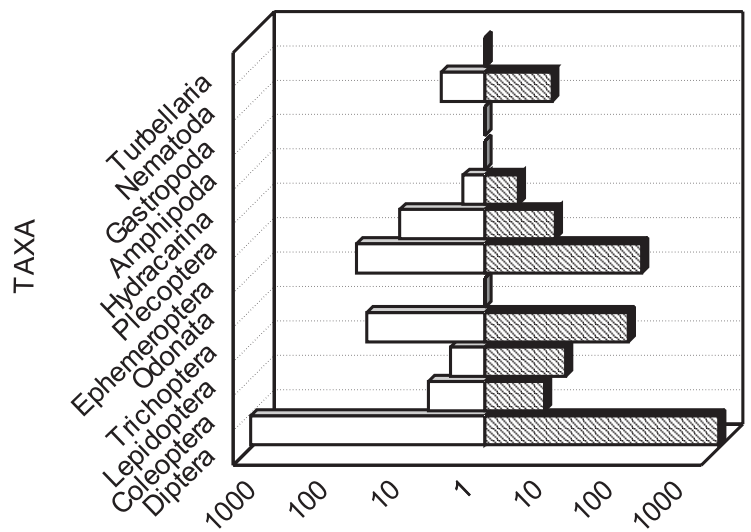

C

ÁREA
$\square$ FECHADA

⿴囗大BERTA

Figura 3: Densidade relativa (log 10) de invertebrados encontrados no substrato rochoso, coletado: A) no riacho, B) por período e C) por área. 
Tabela III

Resultado da análise de variância (ANOVA) aplicada para os dados de abundância de invertebrados no substrato vegetal coletado no Córrego Itaúna.

\begin{tabular}{lllllll}
\hline \multirow{2}{*}{ Fonte de variação } & \multicolumn{3}{c}{ Chironomidae } & \multicolumn{3}{c}{ Total } \\
\cline { 2 - 7 } & $\mathrm{GL}$ & $\mathrm{F}$ & $\mathrm{P}$ & $\mathrm{GL}$ & $\mathrm{F}$ & $\mathrm{P}$ \\
\hline Período & 1 & $26,636^{*}$ (seco) & 0,000 & 1 & 3,121 & 0,085 \\
Área & 1 & 3,463 & 0,071 & 1 & $4,185^{* *}$ (aberta) & 0,048 \\
Trecho & 1 & 0,216 & 0,645 & 1 & $12,301^{*}$ (corredeira) & 0,001 \\
Período x Área & 1 & $6,272^{* *}$ & $0,017^{* *}$ & 1 & $7,004^{* *}$ & 0,012 \\
Área x Trecho & 1 & 0,057 & 0,813 & 1 & 0,285 & 0,596 \\
Período x Trecho & 1 & 0,748 & 0,393 & 1 & 2,199 & 0,146 \\
Período x Área x Trecho & 1 & $10,995^{*}$ & $0,002^{*}$ & 1 & $5,199^{* *}$ & 0,028 \\
\cline { 2 - 7 } $\mathbf{R}^{2}$ & \multicolumn{3}{c}{0.749} & & & 0.565 \\
\end{tabular}

Nível do fator com maior abundância: ${ }^{*} \mathrm{P}<0,01 ;{ }^{* *} \mathrm{P}<0,05$.

Para verificar a influência dos diversos fatores (período, área e trecho) sobre a densidade e riqueza de macroinvertebrados nos substratos de fundo (vegetal, rochoso e sedimento), foi feita uma análise de variância (Tab. IX) que mostrou diferenças significativas entre período (seco) e área (aberta), tanto para densidade como para a riqueza de espécies. Em termos de densidade nos vários substratos, apesar da análise de variância não mostrar resultados significativos, é possível verificar pelos dados obtidos uma predominância no substrato rochoso (Tab. X). Para a riqueza de espécies, valores significativos entre substratos foram encontrados, com predomínio de espécies no substrato vegetal.

A análise de DCA, dos dados de densidade de macroinvertebrados nos substratos, mostrou que a composição varia de acordo com o tipo de substrato de fundo. No quadrante à direita, encontramos os organismos predominantes no sedimento; na parte superior a esquerda, aqueles predominantes no substrato rochoso e, na parte inferior do mesmo lado, os organismos associados ao substrato vegetal (Fig. 5). Uma distinção nítida entre os tipos de substratos foi também encontrada (Fig. 6). Esta distinção entre substratos foi reforçada pelos resultados da análise de variância (ANOVA) aplicada para os "scores" dos dois 


\section{Tabela IV}

\section{Macroinvertebrados encontrados no substrato rochoso, coletado no Córrego Itaúna, no período de outubro/1990 a agosto/1991.}

Filo Platyhelminthes

Filo Nematoda

Filo Annelida

Classe Oligochaeta

Filo Mollusca

Família Ancylidae

Filo Arthropoda

Classe Crustacea

Ordem Amphipoda

Família Talitridae

Hyalella azteca

Classe Arachnida

Ordem Acarina (Hydracarina)

Classe Insecta

Ordem Plecoptera

Família Gripopterygidae

Gripopterix

Paragripopterix

Tupiperla

Ordem Ephemeroptera

Família Leptohyphidae Leptohyphes

Famíla Leptophlebiidae

Família Baetidae

Baetis

Baetodes

Dactylobaetis

Ordem Odonata

Subordem Anisoptera

Família Libellulidae

Ordem Trichoptera

Família Hydropsychidae

Smicridea

Leptonema

Família Hydroptilidae

Hydroptila
Leucotrichia

Neotrichia

Zumatrichia

Família Leptoceridae

Grumichella

Família Philopotamidae

Dolophilodes

Família Glossosomatidae

Protoptila

Ordem Lepidoptera

Família Pyralidae

Petrophila

Ordem Coleoptera

Família Elmidae

Heterelmis

Ordem Diptera

Família Ceratopogonidae

Família Chironomidae

Pentaneura

Cardiocladius

Corynoneura

Thienemanniella

Cricotopus

Cricotopus./Orthocladius

Lopescladius

Nanocladius

Rheocricotopus

Parametriocnemus

Orthocladiinae (subfamília)

Beardius

Polypedilum

Nimbocera paulensis

Tanytarsus

Rheotanytarsus

Família Empididae

Hemerodromia

Famíla Psychodidae

Maruina

Família Simuliidae 


\section{Tabela V}

\section{Abundância (N) e densidade relativa (\%) dos invertebrados do substrato rochoso, coletado no Córrego Itaúna, por período e por área.}

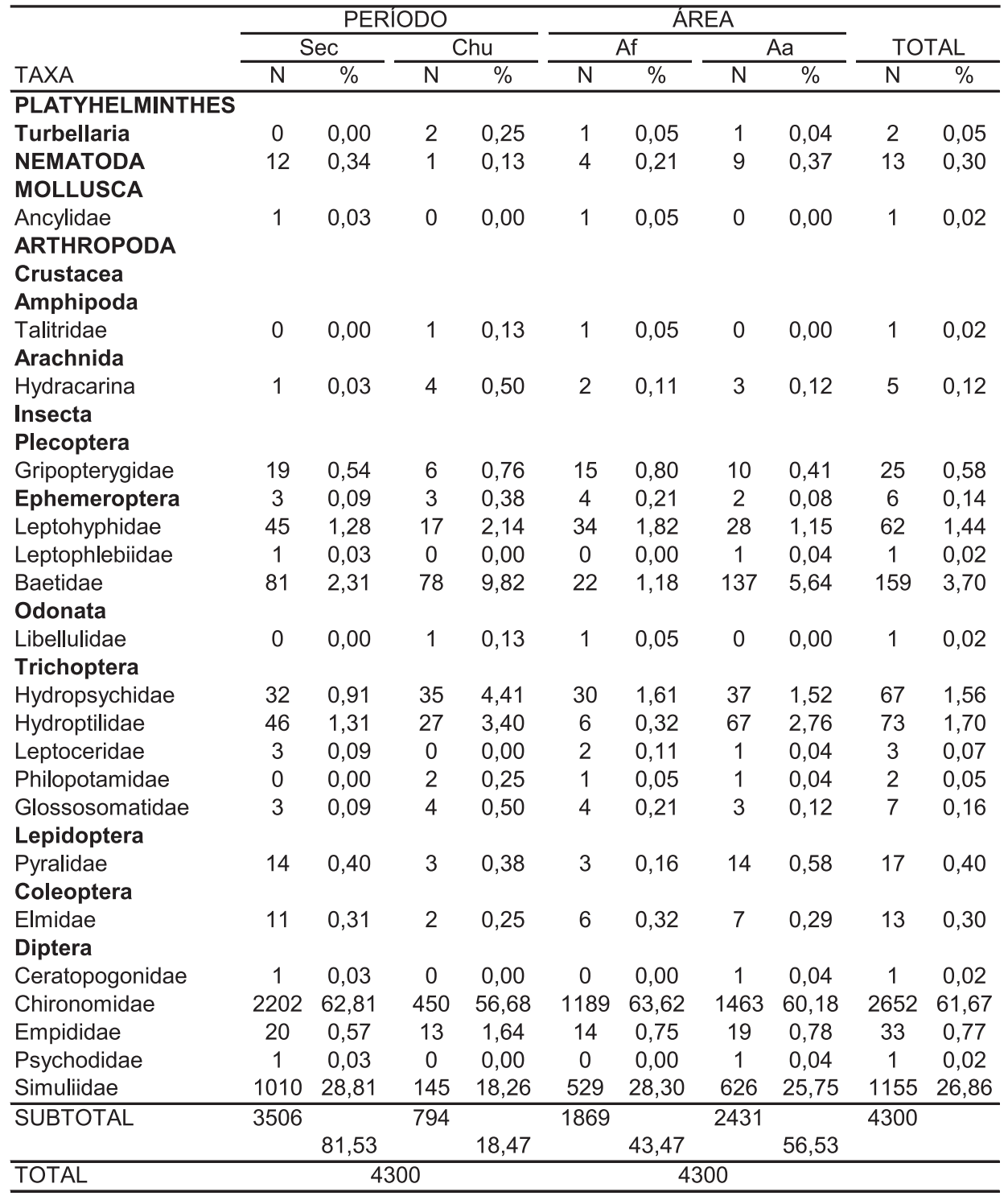

Sec: seco; Chu: chuvoso; Af: área fechada; Aa:área aberta 


\section{Tabela VI}

Resultado da análise de variância (ANOVA) aplicada para os dados de abundância dos invertebrados do substrato rochoso coletado no Córrego Itaúna.

\begin{tabular}{|c|c|c|c|c|c|c|c|c|c|}
\hline \multirow{2}{*}{$\begin{array}{l}\text { Fonte de } \\
\text { variação }\end{array}$} & \multicolumn{3}{|c|}{ Chironomidae } & \multicolumn{3}{|c|}{ Simuliidae } & \multicolumn{3}{|c|}{ Total } \\
\hline & $\overline{\mathrm{GL}}$ & $F$ & $P$ & $\mathrm{GL}$ & $\mathrm{F}$ & $P$ & GL & $\mathrm{F}$ & $P$ \\
\hline Período & 1 & $56,816^{*(\mathrm{sec} 0)}$ & 0,000 & 1 & $43,437^{*}$ (seco) & 0,000 & 1 & $97,938^{*(\mathrm{sec} 0)}$ & 0,000 \\
\hline Área & 1 & 3,585 & 0,069 & 1 & 0,001 & 0,971 & 1 & 2,936 & 0,099 \\
\hline Período x Área & 1 & 1,544 & 0,224 & 1 & 0,445 & 0,511 & 1 & 2,071 & 0,162 \\
\hline
\end{tabular}

$\mathbf{R}^{2}$

0.810

0.766

0.823

Nível do fator com maior abundância: ${ }^{*} \mathrm{P}<0,01 ;{ }^{* *} \mathrm{P}<0,05$.

eixos obtidos a partir da análise de DCA, indicando uma separação significante para substrato (DCA1: $F=148,0, P=0,000$; DCA2: $F=94,4$, $\mathrm{P}=0,000)$ nos dois eixos.

Os dados de correlação dos dois eixos de DCA (Tab. XI) mostraram que Sphaeriidae e Anisoptera tiveram correlação positiva com o primeiro eixo (DCA1) e que as famílias Leptohyphidae, Hydropsychidae, Simuliidae, Gripopterygidae, Empididae, Baetidae e Chironomidae tiveram uma correlação negativa. Para o primeiro eixo, os organismos correlacionados positivamente são comuns no sedimento. Para os correlacionados negativamente, os táxons são abundantes no substrato vegetal e no substrato rochoso.

A Ordem Diptera sobressai nos três substratos, sendo os quironomídeos os que apresentam uma maior riqueza e densidade (com exceção do substrato vegetal, onde a densidade de quironomídeos e simulídeos são semelhantes). Dentro dos quironomídeos, as larvas da Subfamília Orthocladiinae sobressaem. (Fig. 7). No substrato vegetal de trechos de corredeiras sobressaíram os táxons Corynoneura $(44,1 \%)$ e Rheotanytarsus $(27,8 \%)$; e no mesmo substrato em trechos de poção predominaram Rheotanytarsus (41,8\%) e Corynoneura $(22,6 \%)$. No substrato rochoso os mais abundantes foram Cricotopus $(42,0 \%)$ e Rheotanytarsus (39,7\%); e no sedimento predominaram Polypedilum $(51,2 \%)$ e Rheotanytarsus $(9,8 \%)$. Na Fig. 7 , foram suprimidos os gêneros que apresentaram menos de 5 indivíduos, para efeito de melhor visualização dos gêneros dominantes. Também nesta figura, o item Tanypodinae na legenda representa os gêneros Ablabesmyia, Fittkaumyia, Labrundinea, Larsia e Pentaneura. 


\section{Tabela VII}

Macroinvertebrados encontrados no sedimento, coletado no Córrego

Itaúna, no período de outubro/1990 a agosto/1991.

Filo Platyhelminthes

Filo Nematoda

Filo Annelida

Classe Oligochaeta

Filo Mollusca

$$
\begin{gathered}
\text { Família Sphaeriidae } \\
\text { Pisidium }
\end{gathered}
$$

Filo Arthropoda

Classe Insecta

Ordem Odonata

Subordem Zygoptera

Família Gomphidae

Phyllocycla

Progomphus

Ordem Trichoptera

Família Glossosomatidae

Protoptila

Ordem Coleoptera

Família Elmidae

Heterelmis

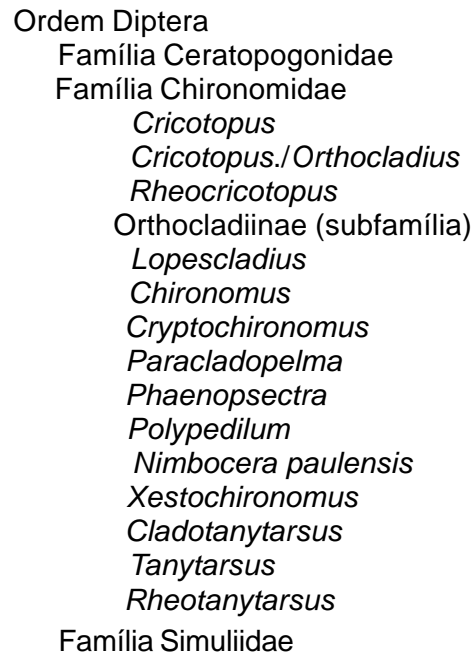

Família Ceratopogonidae

Família Chironomidae

Cricotopus

Cricotopus./Orthocladius

Rheocricotopus

Orthocladiinae (subfamília)

Lopescladius

Chironomus

Cryptochironomus

Paracladopelma

Phaenopsectra

Polypedilum

Nimbocera paulensis

Xestochironomus

Cladotanytarsus

Tanytarsus

Rheotanytarsus

Família Simuliidae 


\section{Tabela VIII}

Abundância (N) e densidade relativa (\%) dos invertebrados presentes no sedimento, coletado no Córrego Itaúna, por período e por área.

\begin{tabular}{|c|c|c|c|c|c|c|c|c|}
\hline \multirow[b]{3}{*}{ TAXA } & \multicolumn{4}{|c|}{ PERÍODO } & \multicolumn{4}{|c|}{ ÁREA } \\
\hline & \multicolumn{2}{|c|}{ Sec } & \multicolumn{2}{|c|}{ Chu } & \multicolumn{2}{|c|}{ Af } & \multicolumn{2}{|c|}{$\mathrm{Aa}$} \\
\hline & $\mathrm{N}$ & $\%$ & $\mathrm{~N}$ & $\%$ & $\mathrm{~N}$ & $\%$ & $\mathrm{~N}$ & $\%$ \\
\hline \multicolumn{9}{|c|}{ PLATYHELMINTHES } \\
\hline Turbellaria & 1 & 1,00 & 0 & 0,00 & 1 & 1,45 & 0 & 0,00 \\
\hline NEMATODA & 7 & 7,00 & 2 & 2,44 & 3 & 4,35 & 6 & 5,31 \\
\hline \multicolumn{9}{|l|}{ MOLLUSCA } \\
\hline Sphaeriidae & 35 & 35,00 & 41 & 50,00 & 44 & 63,77 & 32 & 28,32 \\
\hline \multicolumn{9}{|l|}{ ARTHROPODA } \\
\hline \multicolumn{9}{|l|}{ Insecta } \\
\hline \multicolumn{9}{|l|}{ Odonata } \\
\hline Gomphidae & 7 & 7,00 & 2 & 2,44 & 3 & 4,35 & 6 & 5,31 \\
\hline \multicolumn{9}{|l|}{ Trichoptera } \\
\hline $\begin{array}{l}\text { Glossosomatidae } \\
\text { Coleoptera }\end{array}$ & 1 & 1,00 & 0 & 0,00 & 0 & 0,00 & 1 & 0,88 \\
\hline Elmidae & 0 & 0,00 & 1 & 1,22 & 0 & 0,00 & 1 & 0,88 \\
\hline \multicolumn{9}{|l|}{ Diptera } \\
\hline Ceratopogonidae & 1 & 1,00 & 0 & 0,00 & 0 & 0,00 & 1 & 0,88 \\
\hline Chironomidae & 47 & 47,00 & 36 & 43,90 & 17 & 24,64 & 66 & 58,41 \\
\hline Simuliidae & 1 & 1,00 & 0 & 0,00 & 1 & 1,45 & 0 & 0,00 \\
\hline \multirow[t]{2}{*}{ SUBTOTAL } & 100 & & 82 & & 69 & & 113 & \\
\hline & \multirow{2}{*}{\multicolumn{4}{|c|}{182}} & & 37,91 & & 62,09 \\
\hline TOTAL & & & & & \multicolumn{4}{|c|}{182} \\
\hline
\end{tabular}

Sec: seco; Chu: chuvoso; Af: área fechada; Aa:área aberta

Tabela IX

Resultado da análise de variância (ANOVA) aplicada para os dados de densidade e riqueza de espécies de invertebrados associados aos substratos vegetal, rochoso e sedimento.

\begin{tabular}{|c|c|c|c|c|c|c|c|c|c|}
\hline \multirow[t]{3}{*}{ Fatores de variação } & \multirow{2}{*}{\multicolumn{3}{|c|}{ Densidade }} & \multicolumn{6}{|c|}{ Riqueza de espécies } \\
\hline & & & & \multicolumn{3}{|c|}{ indivíduos } & \multicolumn{3}{|c|}{ volume } \\
\hline & $\overline{G L}$ & $\mathrm{~F}$ & $\mathrm{P}$ & GL & $\mathrm{F}$ & $\mathrm{P}$ & GL & $\mathrm{F}$ & $\mathrm{P}$ \\
\hline Período & 1 & $23,348^{*}($ seco) & 0,000 & 1 & 3,108 & 0,088 & 1 & $13,856^{*}$ (seco) & 0,001 \\
\hline Área & 1 & $7,823^{*}$ (aberta) & 0,006 & 1 & 3,232 & 0,082 & 1 & $4,885^{\star *}$ (aberta) & 0,035 \\
\hline Substrato & 2 & $1,942^{\text {(rochoso) }}$ & 0,149 & 2 & $6,290^{*(\text { vegetal })}$ & 0,005 & 2 & $5,890 *$ (vegetal) & 0,007 \\
\hline Período x Área & 1 & 0,990 & 0,322 & 1 & 0,001 & 0,975 & 1 & 0,768 & 0,388 \\
\hline Área x Substrato & 2 & 0,146 & 0,865 & 2 & 1,494 & 0,240 & 2 & 0,568 & 0,572 \\
\hline Período x Substrato & 2 & $6,327^{*}$ & $0,003^{*}$ & 2 & $7,173^{*}$ & 0,003 & 2 & 0,471 & 0,629 \\
\hline Período x Área x Substrato & 2 & 1,084 & 0,342 & 2 & 0,793 & 0,462 & 2 & 0,201 & 0,819 \\
\hline $\mathbf{R}^{2}$ & & 0.388 & & & 0.552 & & & 0.520 & \\
\hline
\end{tabular}

Os valores de riqueza foram transformados pelo método da Rarefação. Nível do fator com maior densidade ou riqueza: ${ }^{*} \mathrm{P}<0,01 ;{ }^{* \star} \mathrm{P}<0,05$ e o número esperado de espécies é padronizado para 0 número mínimo de indivíduos e para o volume mínimo. 
Tabela $X$

Porcentagem dos táxons de macroinvertebrados nos três tipos de substratos amostrados, calculada a partir dos valores de densidade

\begin{tabular}{|c|c|c|c|c|c|c|c|c|}
\hline \multirow[b]{3}{*}{ Taxa } & \multicolumn{6}{|c|}{ Substrato } & & \\
\hline & \multicolumn{2}{|c|}{ Vegetal } & \multicolumn{2}{|c|}{ Rochoso } & \multicolumn{2}{|c|}{ Sedimento } & \multicolumn{2}{|c|}{ Total } \\
\hline & $\mathrm{n}$ & $\%$ & $\mathrm{n}$ & $\%$ & $\mathrm{n}$ & $\%$ & $\mathrm{n}$ & $\%$ \\
\hline PLATYHELMINTHES Turbellaria & 160 & 65,8 & 12 & 4,9 & 71 & 29,2 & 243 & 0,39 \\
\hline NEMATODA & 35 & 4,6 & 81 & 10,8 & 637 & 84,6 & 753 & 1,21 \\
\hline MOLLUSCA Ancylidae & 4 & 40,0 & 6 & 60,0 & - & - & 10 & 0,02 \\
\hline Sphaeriidae & 22 & 0,4 & - & - & 5379 & 99,6 & 5401 & 8,67 \\
\hline \multicolumn{9}{|l|}{ ARTHROPODA } \\
\hline Crustacea AmphipodaTalitridae & 4 & 40,0 & 6 & 60,0 & - & - & 10 & 0,02 \\
\hline Decapoda Aeglidae & 17 & 100,0 & - & - & - & - & 17 & 0,03 \\
\hline Trichodactilidae & 4 & 100,0 & - & - & - & - & 4 & 0,01 \\
\hline Arachnida Hydracarina & 9 & 23,1 & 30 & 76,9 & - & - & 39 & 0,06 \\
\hline Insecta Collembola Isotomidae & 26 & 100,0 & - & - & - & - & 26 & 0,04 \\
\hline Megaloptera Corydalidae & 13 & 100,0 & - & - & - & - & 13 & 0,02 \\
\hline Plecoptera Gripopterygidae & 1782 & 92,1 & 153 & 7,9 & - & - & 1935 & 3,11 \\
\hline Perlidae & 17 & 100,0 & - & - & - & - & 17 & 0,03 \\
\hline Ephemeroptera & 173 & 82,4 & 37 & 17,6 & - & - & 210 & 0,34 \\
\hline Leptohyphidae & 604 & 61,2 & 383 & 38,8 & - & - & 987 & 1,58 \\
\hline Leptophlebiidae & 22 & 78,6 & 6 & 21,4 & - & - & 28 & 0,04 \\
\hline Baetidae & 191 & 16,3 & 981 & 83,7 & - & - & 1172 & 1,88 \\
\hline Odonata Zygoptera & 17 & 100,0 & - & - & - & - & 17 & 0,03 \\
\hline Anisoptera & 4 & 100,0 & - & - & - & - & 4 & 0,01 \\
\hline Calopterygidae & 4 & 100,0 & - & - & - & - & 4 & 0,01 \\
\hline Aeshnidae & 9 & 100,0 & - & - & - & - & 9 & 0,01 \\
\hline Coenagrionidae & 4 & 100,0 & - & - & - & - & 4 & 0,01 \\
\hline Libellulidae & - & - & 6 & 100,0 & - & - & 6 & 0,01 \\
\hline Gomphidae & - & - & - & - & 637 & 100,0 & 637 & 1,02 \\
\hline Trichoptera Hydropsychidae & 409 & 49,8 & 413 & 50,2 & - & - & 822 & 1,32 \\
\hline Hydroptilidae & 4 & 0,9 & 450 & 99,1 & - & - & 454 & 0,73 \\
\hline Leptoceridae & 26 & 59,1 & 18 & 40,9 & - & - & 44 & 0,07 \\
\hline Philopotamidae & 13 & 52,0 & 12 & 48,0 & - & - & 25 & 0,04 \\
\hline Calamoceratidae & 17 & 100,0 & - & - & - & - & 17 & 0,03 \\
\hline Glossosomatidae & - & - & 43 & 37,7 & 71 & 62,3 & 114 & 0,18 \\
\hline Lepidoptera Tortricidae & 4 & 100,0 & - & - & - & - & 4 & 0,01 \\
\hline Pyralidae & - & - & 104 & 100,0 & - & - & 104 & 0,17 \\
\hline Coleoptera Gyrinidae & 18 & 100,0 & - & - & - & - & 18 & 0,03 \\
\hline Elmidae & 733 & 82,9 & 80 & 9,0 & 71 & 8,0 & 884 & 1,42 \\
\hline Limnichidae & 13 & 100,0 & - & - & - & - & 13 & 0,02 \\
\hline Staphylinidae & 4 & 100,0 & - & - & - & - & 4 & 0,01 \\
\hline Dytiscidae & 4 & 100,0 & - & - & - & - & 4 & 0,01 \\
\hline Diptera Ceratopogonidae & 13 & 14,4 & 6 & 6,7 & 71 & 78,9 & 90 & 0,14 \\
\hline Chironomidae & 8312 & 27,2 & 16862 & 55,2 & 5382 & 17,6 & 30556 & 49,04 \\
\hline Empididae & 235 & 53,7 & 203 & 46,3 & - & - & 438 & 0,70 \\
\hline Ephydridae & 8 & 100,0 & - & - & - & - & 8 & 0,01 \\
\hline Muscidae & 4 & 100,0 & - & - & - & - & 4 & 0,01 \\
\hline Psychodidae & 13 & 68,4 & 6 & 31,6 & - & - & 19 & 0,03 \\
\hline Scatophagidae & 27 & 100,0 & - & - & - & - & 27 & 0,04 \\
\hline Sciomyziidae & 4 & 100,0 & - & - & - & - & 4 & 0,01 \\
\hline Simuliidae & 9915 & 57,9 & 7129 & 41,7 & 71 & 0,4 & 17115 & 27,47 \\
\hline \multirow{2}{*}{ TOTAL } & 22897 & & 27027 & & 12390 & & 62314 & \\
\hline & & 36,7 & & 43,4 & & 19,9 & & \\
\hline
\end{tabular}

n: número de indivíduos/ m3 em cada substrato 


\section{Tabela XI}

Valores da correlação dos principais táxons de invertebrados nos dois primeiros eixos da DCA, com base nas amostras da coleta específica (substrato vegetal, rochoso e sedimento) coletadas no Córrego Itaúna

\begin{tabular}{|c|c|c|c|c|}
\hline \multirow[b]{2}{*}{ Taxa } & \multicolumn{2}{|c|}{ Correlação de Pearson } & \multicolumn{2}{|c|}{ Correlação de Spearman } \\
\hline & DCA1 & DCA2 & DCA1 & DCA2 \\
\hline Platyhelminthes & $-0,294$ & $-0,381$ & $-0,142$ & $-0,417$ \\
\hline Nematoda & $-0,178$ & 0,494 & 0,214 & 0,547 \\
\hline Sphaeriidae & 0,927 & $-0,215$ & 0,748 & $-0,209$ \\
\hline Gripopterygidae & $-0,720$ & $-0,266$ & $-0,749$ & $-0,315$ \\
\hline Ephemeroptera & $-0,531$ & $-0,315$ & $-0,569$ & $-0,335$ \\
\hline Leptohyphidae & $-0,746$ & $-0,058$ & $-0,638$ & $-0,054$ \\
\hline Baetidae & $-0,703$ & 0,244 & $-0,746$ & 0,258 \\
\hline Zygoptera & $-0,275$ & $-0,369$ & $-0,349$ & $-0,415$ \\
\hline Anisoptera & 0,508 & $-0,326$ & 0,422 & $-0,340$ \\
\hline Hydropsychidae & $-0,737$ & 0,109 & $-0,710$ & 0,065 \\
\hline Hydroptilidae & $-0,349$ & 0,587 & $-0,375$ & 0,575 \\
\hline Leptoceridae & $-0,297$ & 0,046 & $-0,272$ & 0,091 \\
\hline Glossosomatidae & $-0,056$ & 0,609 & 0,053 & 0,531 \\
\hline Pyralidae & $-0,259$ & 0,523 & $-0,244$ & 0,486 \\
\hline Elmidae & $-0,538$ & $-0,405$ & $-0,466$ & $-0,455$ \\
\hline Chironomidae & $-0,706$ & 0,333 & $-0,385$ & 0,235 \\
\hline Empididae & $-0,650$ & $-0,011$ & $-0,689$ & 0,027 \\
\hline Simuliidae & $-0,844$ & 0,056 & $-0,709$ & 0,016 \\
\hline
\end{tabular}

Valores de correlação maiores que 0,50 foram considerados significativos. 

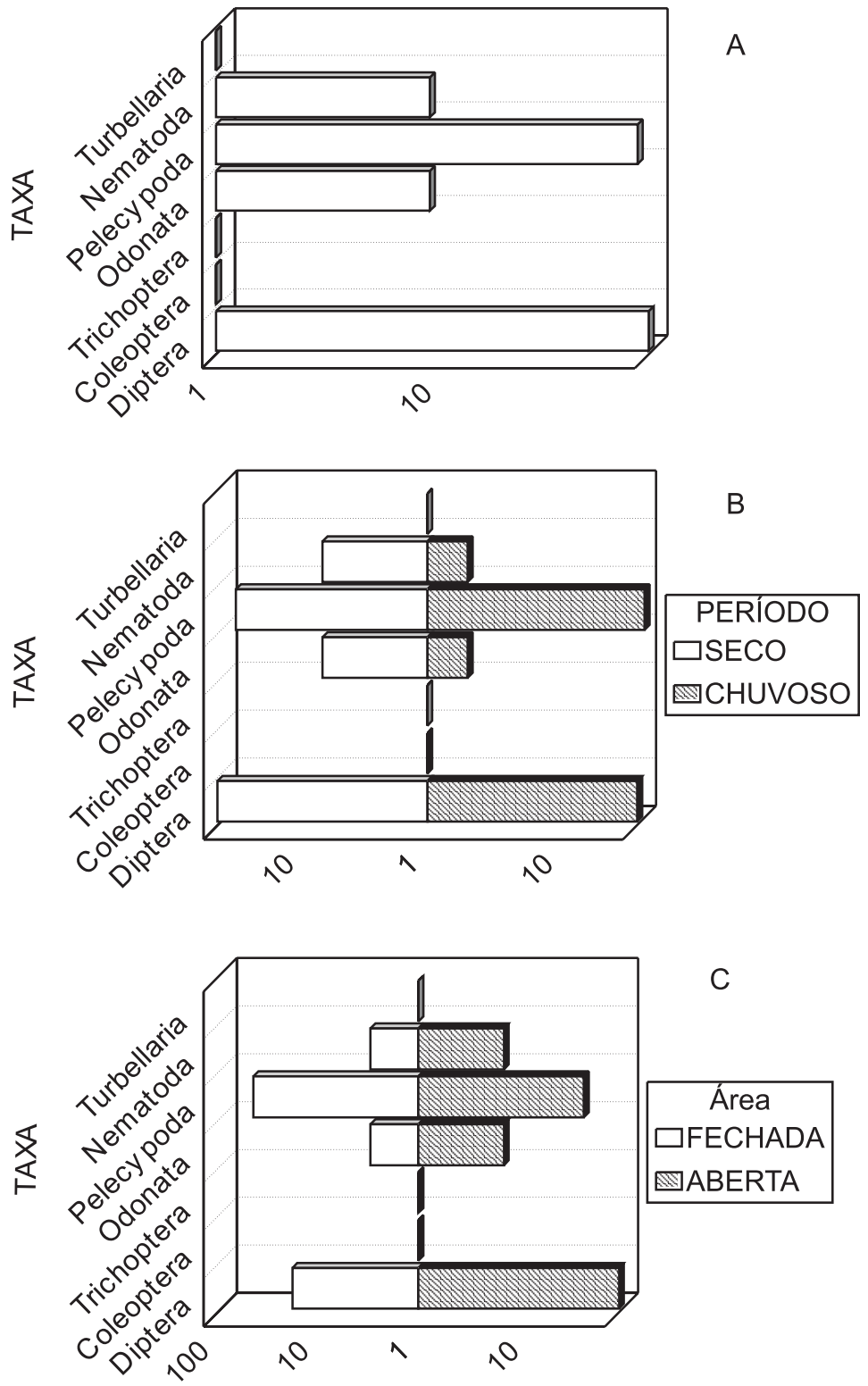

Figura 4: Densidade relativa (log 10) de invertebrados encontrados no sedimento, coletado: A: no riacho, B: por período e C: por área. 


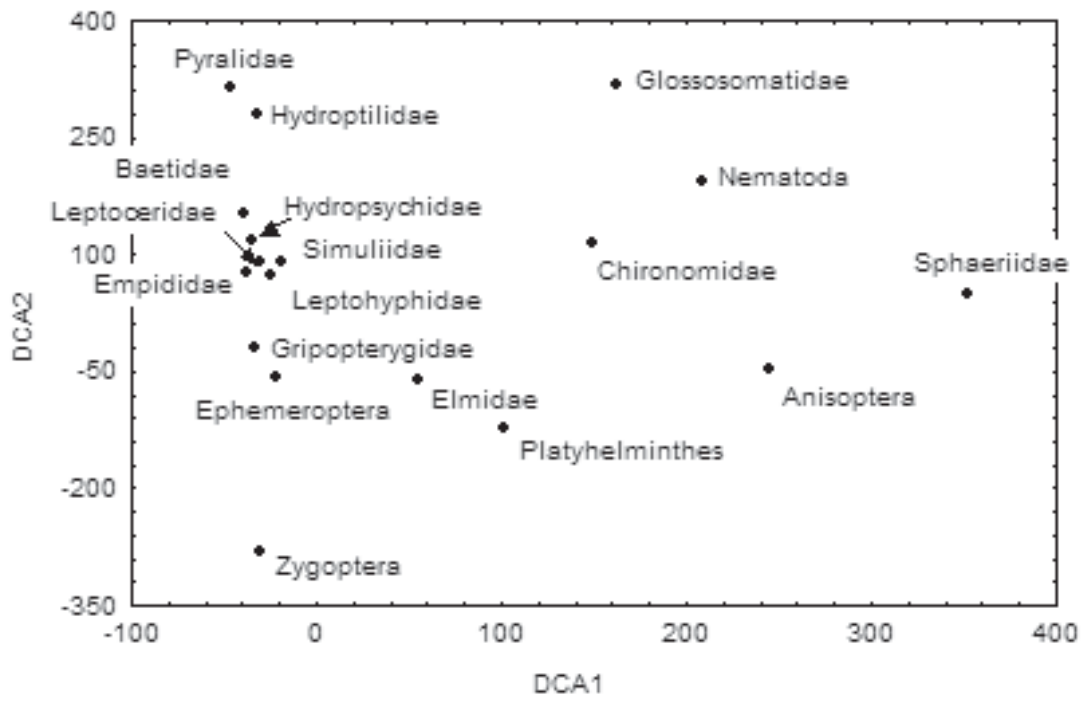

Figura 5: Ordenação da DCA de táxons de invertebrados, a partir dos dados de densidade dos organismos coletados nos substratos de fundo vegetal, rochoso e sedimento. Autovalores: Eixo1=0,576705; Eixo2=0,173895.

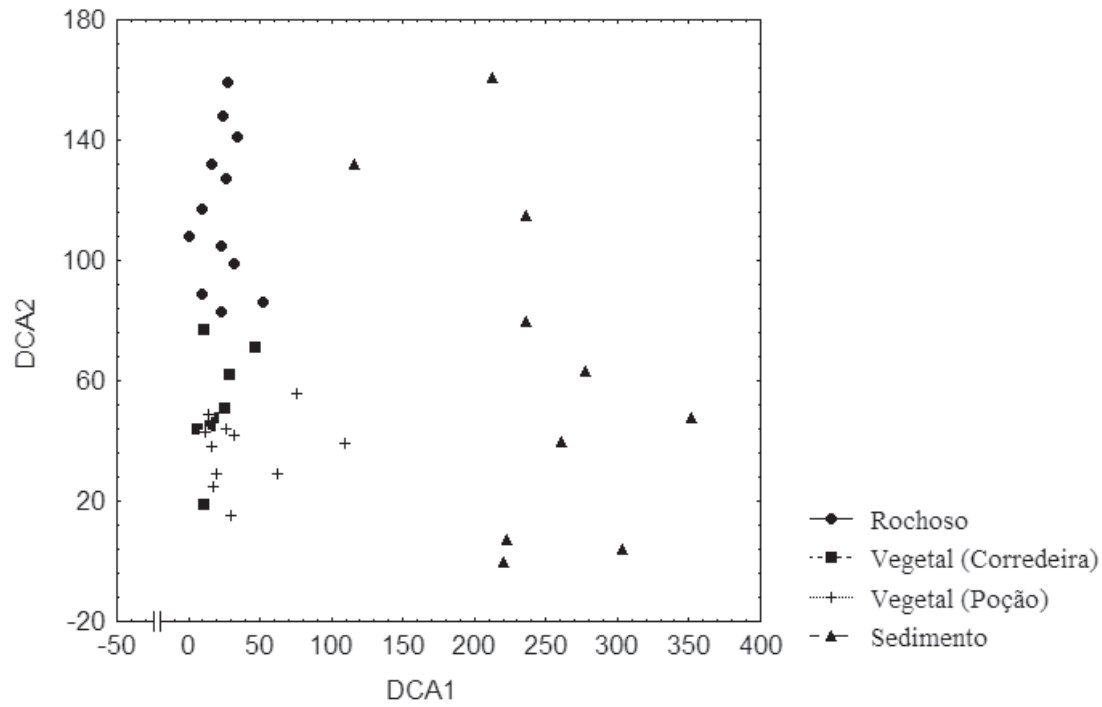

Figura 6: Ordenação da DCA de unidades amostrais, a partir dos dados de densidade dos macroinvertebrados coletados nos substratos de fundo vegetal, rochoso e sedimento. 

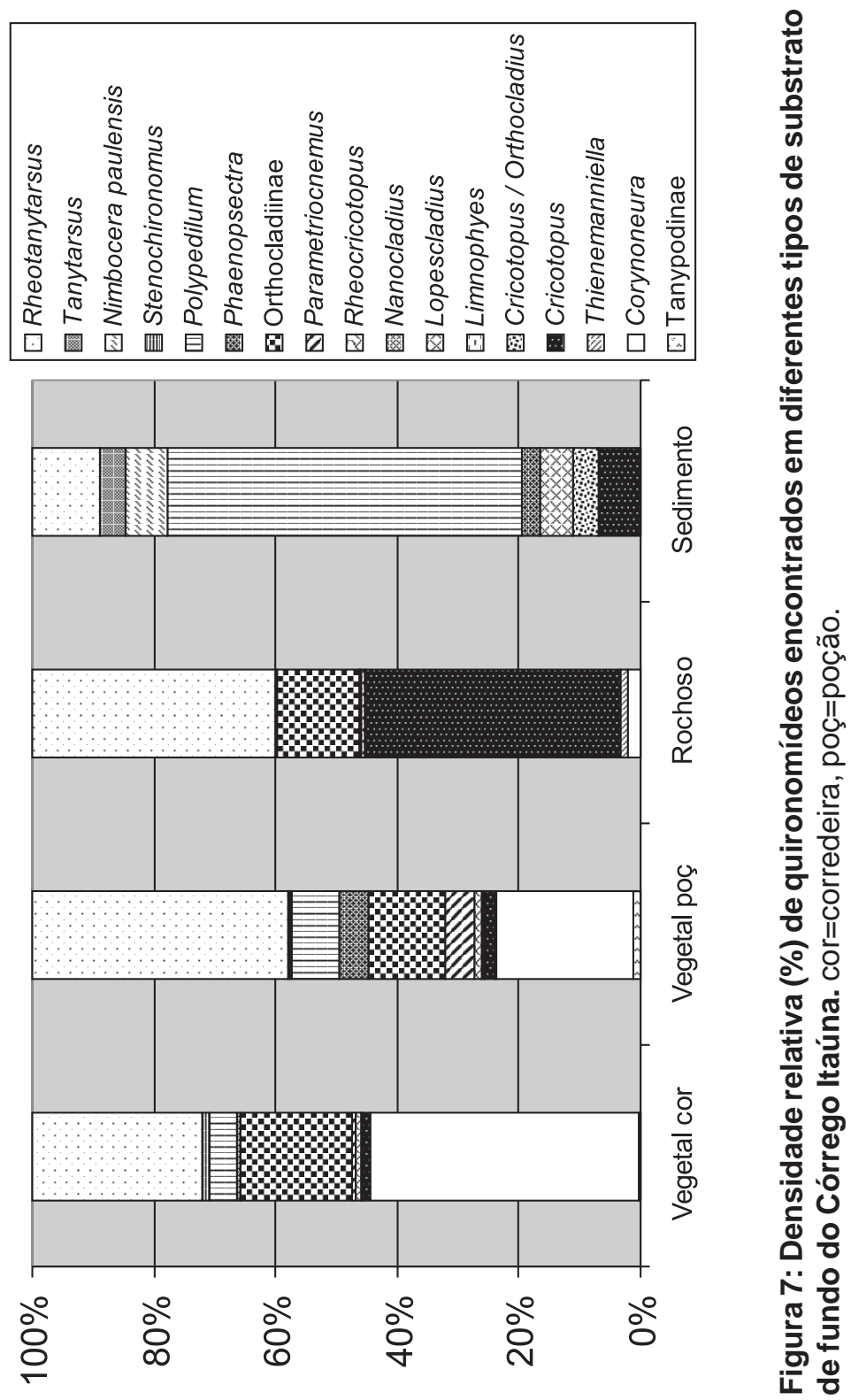


\section{Discussão}

\section{Substrato vegetal}

Os táxons de insetos predominantes no substrato vegetal do Córrego Itaúna, como Diptera (Simuliidae e Chironomidae), Plecoptera (Gripopterygidae), Ephemeroptera (Leptohyphidae), Coleoptera (Elmidae) e Trichoptera (Hydpsychidae) são citados na literatura (Wright et al., 1984), como grupos característicos de regiões montanhosas. Sucullion et al. (1982) verificaram que os Chironomidae eram abundantes em poções e Simullidae em corredeiras, como também ocorreu em amostras de substrato vegetal do Córrego Itaúna. Os quironomídeos utilizam partículas finas para alimentação e construção de tubos (Sucullion et al., 1982) e isto é talvez uma explicação para sua maior abundância no substrato vegetal em poções e no período seco. Nestes hábitats, a probabilidade de remoção das partículas pela correnteza é pequena.

Chironomidae é um grupo importante de insetos aquáticos, freqüentemente ocorrendo em altas densidades e diversidade, na maioria dos tipos de ecossistemas aquáticos (Merritt \& Cummins, 1984). Dentre os quironomídeos existem espécies detritívoras, fragmentadoras, coletoras acumuladoras e filtadoras (Egglishaw, 1964; Merritt \& Cummins, 1984). Segundo Walker $(1986,1988)$, um canal principal de transferência de energia no igapó, nos rios e riachos da floresta na Amazônia é constituído pelos quironomídeos, que são consumidores de fungos e de detritos foliares, e servem como alimento básico para predadores (camarões, insetos aquáticos e pequenos peixes). Segundo Walker (1986), os quironomídeos são os colonizadores dominantes do folhiço submerso nas águas amazônicas (igapó e riachos).

A maior abundância de Simuliidae no período chuvoso e em corredeiras pode ser relacionada à corrente da água, através da qual estes obtém os alimentos, e à presença de estruturas que permitam a sua fixação em objetos submersos (de origem vegetal ou rochoso). Segundo Minshall \& Minshall (1977), Simuliidae são encontrados em áreas de velocidade da corrente elevada. Segundo Merritt \& Cummins (1984), Simuliidae são habitantes de ambiente lóticos, sendo freqüentemente encontradas em correntes rápidas, aderido a substratos submersos, como rochas ou vegetação, por meio de um "falso pé" modificado na região posterior, e através de uma secreção de seda depositada pela larva. Seus "leques" 
labrais expandem-se e permanecem continuamente expostas à corrente para filtrar partículas alimentares microscópicas (Merritt \& Cummins, 1984).

As espécies de Plecoptera vivem somente em ambientes com oxigênio abundante, podendo ocorrer sobre detritos vegetais ou sobre pedras (Pennak, 1978). As ninfas de Gripopterygidae são comumente encontradas sobre folhas caídas e retidas por algum obstáculo, alimentando-se principalmente de folhas (Froehlich, 1966). Segundo Stehr (1987), as ninfas de Leptohyphidae (Ephemeroptera) são organismos com baixo poder de natação e apresentam garras arrastando-se entre rochas e vegetação e alimentando-se de detritos e biota que crescem nas plantas aquáticas e objetos submersos. Elmidae é um grupo de coleópteros de ocorrência junto à vegetação submersa ou sob rochas de riachos de água corrente (Costa et al., 1988). Segundo Oliveira (1991), as larvas de Hydropsychidae (Trichoptera) vivem, em sua maioria, na correnteza de córregos, construindo um abrigo de areia, pedrinhas ou detritos, com uma rede de seda com a parte côncava voltada para a corrente.

A menor densidade total dos organismos no substrato vegetal, encontrada no período chuvoso no Córrego Itaúna pode ser relacionada ao fato de, neste período, ocorrer a lavagem dos organismos bem como das folhas, em função da oscilação do volume de água. Segundo Egglishaw (1964), quando o volume é alto, ocorre uma lavagem e redistribuição de material vegetal e de animais. O "litter" foliar em riachos oferece um hábitat de curta permanência para certos macroinvertebrados (Mackay \& Kalff, 1969 apud Short et al., 1980).

A elevada densidade de organismos encontrados no substrato vegetal na Área aberta do Córrego Itaúna, pode ser relacionada à maior incidência luminosa nesta área. Isto favorece a proliferação de algas aderidas a este substrato, e assim fornece um recurso a mais para ser aproveitado pela comunidade de invertebrados ali presentes.

A maior estabilidade do fundo pedregoso, quando comparado ao substrato arenoso dos poções, poderia explicar a maior densidade de invertebrados no substrato vegetal coletado em corredeiras, pois estas funcionam também como uma ótima barragem de folhas. Boulton et al. (1988) salientam que os pacotes de folhas e detritos aprisionados nas rochas fornecem alimento e abrigo para muitos invertebrados. Mackay \& Kalff (1969) assinalam que as folhas são colonizadas por simulídeos. No Córrego Itaúna, embora tenham sido mais comuns no substrato rochoso, essas larvas foram restritas às folhas aprisionadas na corrente. 


\section{Substrato rochoso}

A maior abundância de dípteros, Simuliidae e Chironomidae (principalmente Rheotanytarsus), no substrato rochoso no Córrego Itaúna, provavelmente pode ser explicada em função de suas atividades alimentares. Estes táxons provavelmente utilizam o substrato rochoso como suporte para fixação, enquanto retiram o alimento carreado pela corrente, pelo mecanismo da filtração. Segundo Boulton et al. (1988), o gênero Rheotanytarsus é comum na superfície de rochas, escondendo-se em suas casas feitas de material particulado fino. Neves (1979) também obteve resultado semelhante em Hampshire (Inglaterra), onde o gênero Rheotanytarsus constituiu o quironomídeo mais abundante em substratos rochosos. Larvas de simulídeos, também filtradoras, são geralmente encontradas agregadas, fixas em superfícies rochosas (Wiley \& Kohler, 1981).

No substrato rochoso do Córrego Itaúna, a maior abundância de invertebrados, e entre estes os dípteros das famílias Simuliidae e Chironomidae, no período seco, provavelmente esteja relacionada à remoção durante o período de maior volume e velocidade da água. $O$ aumento no tamanho das partículas do substrato, apesar de permitir uma maior estabilização em períodos de inundação, pode reduzir a comunidade aí presente, pois com grande atrito de outras partículas menores, ocorre uma diminuição na quantidade de cobertura de musgo e perifiton, diminuindo a disponibilidade de hábitats oportunos (Tikkanen et al., 1994).

O fato dos Simuliidae apresentarem maior abundância no substrato rochoso durante o período seco e no substrato vegetal, durante o período chuvoso no Córrego Itaúna, provavelmente está relacionado ao fator corrente. Como no período chuvoso, o substrato rochoso e os simulídeos, ficam mais sujeitos à ação direta da corrente, este táxon provavelmente migra e procura abrigo no substrato vegetal. A maioria das espécies de simulídeos é encontrada na superfície inferior de rochas, galhos, ou folhas mortas, vivendo em águas de correntes rápidas (Statzner, 1981). Segundo Brennan et al. (1978), a densidade de larvas de quironomídeos (Chironomidae), que domina a fauna de superfície de rochas em riachos montanhosos na Inglaterra, é controlada pela quantidade de material particulado disponível. Este material depende da deposição de partículas suspensas e do crescimento de algas epilíticas. Quando ocorre uma inundação, há uma desnudação de superfícies rochosas, impossibilitando a construção de material epilítico e, consequentemente, limitando a 
densidade larval por regular a disponibilidade de alimento e material para a construção de tubos (Brennan et al., 1978).

No substrato rochoso, a maior densidade da comunidade na Área aberta, do que na fechada, provavelmente se deva ao aumento da incidência luminosa na primeira área, com conseqüente aumento de perifiton (principalmente algas) e de táxons da categoria dos raspadores. Segundo Boulton et al. (1988), a camada de perifiton governa a colonização de certos táxons, como Baetis (Ephemeroptera), enquanto outros, como Simuliidae (Diptera), procuram principalmente espaço, abrigo e adequada velocidade de corrente.

Neves (1979), em investigação experimental de colonização, introduziu rochas num riacho em Hampshire (Inglaterra) e verificou que os dípteros eram os mais abundantes, sendo seguidos pelos Ephemeroptera e Trichoptera. Cressa (1994) encontrou como grupos mais freqüentes, Diptera, Trichoptera, Ephemeroptera e Coleoptera, em um riacho pouco profundo, de águas rápidas e fundo pedregoso da Venezuela. O mesmo padrão de ocorrência em substrato rochoso foi encontrado no Córrego Itaúna.

A família Hydroptilidae (Trichoptera) foi observada mais na Área aberta, principalmente os gêneros Leucotrichia e Zumatrichia (este último, não citado para o Brasil, mas de acordo com R. Guahyba, existem indícios de sua ocorrência em nosso país). Estes dois gêneros são principalmente raspadores e coletores-acumuladores, vivendo em habitat lótico-erosional (Merritt \& Cummins, 1984).

Em Leucotrichiini (representada por Leucotrichia e Zumatrichia), as larvas vivem livremente até o $5^{\circ}$ instar, quando fixam às rochas suas casas de seda, parecendo-se com um casulo de sanguessuga (Stehr, 1987). A larva estende sua cabeça e tórax através de um pequeno buraco na casa de seda, para raspar diatomáceas e partículas (Stehr, 1987). Egglishaw (1964) também encontrou larvas de Hydroptilidae aderidas em rochas com algas.

\section{Sedimento}

No sedimento de poções do Córrego Itaúna, houve o predomínio de Diptera (Chironomidae) e Pelecypoda (família Sphaeridae, gênero Pisidium), e em menor abundância, Odonata (Gomphidae) e Nematoda. Pisidium e Chironomidae, são animais comumente associados com sedimentos finos (Minshall \& Minshall, 1977). 
Doeg et al. (1989), em um estudo experimental de colonização de frações inorgânicas de substrato em um rio da Austrália, encontrou que o gênero Pisidium foi um dos principais táxons presentes no substrato arenoso. Ormerod (1988), estudando a microdistribuição de macroinvertebrados em um rio do País de Gales (Reino Unido), também observou a associação de Pisidium com substrato fino. Hawkins et al. (1983), também observaram a ocorrência de moluscos em substratos arenosos em riachos de Oregon e Califórnia (EUA). Segundo Pennak (1989), os moluscos comuns em pequenos riachos são da família Sphaeriidae, encontrados em todos os tipos de fundo, com exceção de argila e rochas.

A ocorrência de quironomídeos no Córrego Itaúna parece estar associada à presença de detritos no sedimento, que acumulam-se durante o período seco. De acordo com Minshall \& Minshall (1977), a família Chironomidae mostra grande afinidade com a quantidade de detritos presentes no substrato.

Os gêneros Progomphus e Aphylla (família Gomphidae) tem o hábito de se esconder no sedimento de riachos, principalmente, em poções (Merritt \& Cummins, 1984). Progomphus está adaptado a cavar em leitos arenosos de rios e lagos (Pérez, 1988). A perna grossa e curta da maioria dos gêneros de Gomphidae impossibilita que a larva suba em talos delgados para transformação, por isso a emergência geralmente ocorre na areia da margem, ou na superfície rugosa de toras e rochas (Merritt \& Cummins, 1984). Aphylla apresenta o seguimento 10 alongado, a qual funciona como sifão, e, dessa forma, as larvas sobrevivem em sedimento profundo (Merritt \& Cummins, 1984). No Córrego Itaúna encontramos o gênero Phyllocycla semelhante ao gênero Aphylla.

Segundo Lenat et al. (1981), o substrato arenoso geralmente é um lugar de instabilidade. Durante períodos de baixa vazão, este substrato pode tornar-se estável, permitindo dessa forma o crescimento de perifiton e sua associação com macroinvertebrados. Isto poderia explicar a maior densidade de macroinvertebrados no sedimento coletado no período seco para o Córrego Itaúna.

\section{Comparação dos substratos}

No Córrego Itaúna, a maior densidade e riqueza de espécies de invertebrados encontrados no período seco e na Área aberta, provavelmente esteja ligada ao fator corrente e alimento. No período seco os organismos 
não são facilmente removidos pela corrente de água, cuja velocidade é elevada no período chuvoso. Na Área aberta, a maior incidência luminosa propiciaria uma maior proliferação de organismos produtores e de invertebrados utilizando este recurso alimentar (algas), além do material alóctone vindo de áreas a montante.

No Córrego Itaúna, a maior densidade de organismos no substrato rochoso e a maior riqueza de espécies no substrato vegetal, provavelmente está relacionada à estabilidade e às múltiplas funções do substrato. A estabilidade do substrato refere-se ao grau de resistência ao movimento, sendo geralmente proporcional ao tamanho das partículas do substrato (Resh \& Rosenberg, 1984). O substrato rochoso, mais estável, fornece condições ideais para a população crescer. Assim, o número de invertebrados aumenta sobre uma seqüência crescente de acordo com o tamanho da partícula, ou seja, desde areia até rochas (Minshall \& Minshall, 1977). O hábitat de areia, devido a sua instabilidade, é geralmente considerado uma área de baixa produtividade bêntica (Lenat et al. 1981; Wallace et al., 1988). Wise \& Molles (1979) encontraram mais indivíduos colonizando pequenas $(10 \mathrm{~mm}-25$ $\mathrm{mm}$ ) do que grandes rochas (> $75 \mathrm{~mm}$ ). Segundo Tikkanen et al. (1994), o aumento no tamanho da partícula pode ser importante, pois estabiliza o substrato e reduz a probabilidade da movimentação do substrato durante inundações. Statzner \& Higler (1986), analisando a zonação de invertebrados bênticos desde o Alasca até a Nova Zelândia, verificaram que a fauna mais estável é encontrada em extensões pedregosas.

Gurtz \& Wallace (1984) estudando riachos de Nova Carolina (EUA), verificaram que o substrato é um fator muito importante, influenciando a resposta dos táxons de invertebrados a perturbações como inundações. A maioria dos táxons tem preferência por substratos grosseiros, ao invés de substrato de pequenas partículas. Os grandes substratos requerem maior força a ser imprimida pela correnteza para sua movimentação, sendo fisicamente mais estáveis (Gurtz \& Wallace, 1984). Estes substratos ocorrem onde a velocidade da corrente é alta e são por isso menos suscetíveis à deposição de partículas finas (Gurtz \& Wallace, 1984). A redução na riqueza de espécies e na abundância é comumente associada a áreas de deslocamento da areia. Porém, certas espécies aparentemente preferem este tipo de substrato fino, como larvas de dípteros dos gêneros Chironomus (Resh \& Rosenberg, 1984), e Lopescladius, encontradas em fundo arenoso de riachos (Epler, 1992). Estes dois gêneros foram encontrados no sedimento arenoso do Córrego Itaúna. 
Segundo Mackay \& Kalff (1969) o substrato arenoso oferece baixa variedade de microhábitat e baixo número de espécies, em função da baixa estabilidade deste substrato. Esta situação é a mesma encontrada no Córrego Itaúna, onde no sedimento foram obtidos menores valores de densidade e riqueza de espécies, quando comparado com os outros substratos. O sedimento de riachos não é suficientemente abundante ou estável para fornecer hábitat adequado para invertebrados, principalmente aqueles que em outros hábitats preferem sedimentos finos como efemerópteros e oligoquetas (Brown \& Brussock, 1991).

No Córrego Itaúna, o substrato vegetal comporta um maior número de espécies, pois ele por si só, já é um recurso alimentar, podendo também servir de suporte e abrigo para muitos invertebrados. Segundo Short et al. (1980), o substrato vegetal é importante como fonte alimentar e também funciona como sistema coletor de detritos orgânicos de partículas finas. Dessa forma, é hábitat para os detritívoros que se alimentam dessas partículas, podendo inclusive ser utilizado, diretamente pelos fragmentadores. Segundo Egglishaw (1964), os organismos podem agregar-se em locais onde detritos vegetais são mais abundantes, os quais funcionam como alimento e abrigo. Walker (1988) trabalhando especificamente com "litter" submerso em um riacho da Amazônia Central, relatou observação similar. Mackay \& Kalff (1969) assinalam que a fauna de substrato vegetal inclui espécies que preferem a superfície de folhas expostas à corrente, bem como outras que procuram abrigo entre elas.

Como mencionado anteriormente, o substrato vegetal é colonizado por espécies diferentes, que utilizam as folhas seja para abrigo ou alimentação. As espécies podem utilizar o material foliar em diferentes estágios de degradação dentro do riacho, de acordo com suas necessidades biológicas. Walker (1994) assinalou a preferência de Thraulodes sp (Ephemeroptera) . e Marilia sp. (Trichoptera) por pacotes soltos de "litter" depositados recentemente, enquanto Phylloicus sp (Trichoptera) prefere "littfer" já suficientemente degradado para ser utilizado na construção de abrigo. Mackay \& Kalff (1969), estudando as comunidades de insetos em um pequeno riacho do Canadá, verificaram que, dentre os vários substratos de fundo, as folhas apresentam um alto número de espécies de invertebrados, enquanto que no substrato arenoso uma densidade baixa foi encontrada. Dobson (1994) observou que o "litter" era colonizado principalmente por 
organismos detritívoros, sendo rapidamente consumido, de maneira que a diversidade de espécies no substrato permaneceu baixa. No substrato vegetal amostrado no Córrego Itaúna, por outro lado, encontramos uma diversidade grande de espécies e representativas de vários grupos funcionais.

No Córrego Itaúna, as diferenças de densidade e riqueza dos invertebrados em cada tipo de substrato foram bem representadas na plotagem dos valores obtidos pela DCA. O sedimento foi o substrato com separação bastante evidente em relação aos demais, onde predominaram os grupos, Sphaeriidae e Anisoptera, típicos do substrato arenoso. A separação de um grupo composto pelas famílias Glossomatidae, Pyralidae e Hydroptilidae e de outro grupo composto de Elmidae, Platyhelminthes e Zygoptera, provavelmente está associada à colonização preferencial em diferentes substratos, no caso, substrato rochoso e vegetal.

As larvas de Glossosomatidae raspam diatomáceas e partículas finas orgânicas na superfície superior exposta de rochas em águas correntes, arrastando-se sobre rochas e escondendo-se debaixo da cúpula da casa (Merritt \& Cummins, 1984). As larvas de Pyralidae vivem debaixo de abrigos de seda construídos dentro de depressões na superfície rochosa (Allan,1995). Segundo este autor, formas que crescem aderidas e incrustadas necessitam de substrato que não é facilmente destruído pela corrente, como grandes rochas que são naturalmente mais estáveis. Hydroptilidae foi mais abundante na Área aberta, principalmente Leucotrichia e Zumatrichia. Este táxon é descrito como raspador e coletor acumulador (Merritt \& Cummins, 1984), que fixa às rochas suas casas de seda e raspa diatomáceas e partículas da área em volta (Stehr, 1987). Para o segundo grupo, Elmidae é descrito como de ocorrência na vegetação submersa ou sob rochas de riachos (Costa et al., 1988); Zygoptera é classificado como "escalador", escondendo-se na vegetação ou em "restos" de talos de plantas aquáticas (Merritt \& Cummins, 1984).

No Córrego Itaúna, os quironomídeos predominam em riqueza e densidade de espécies nos substratos analisados. Chironomidae (Diptera) é um grupo importante de insetos aquáticos, freqüentemente ocorrendo em altas densidades e diversidade na maioria dos tipos de ecossistemas aquáticos (Merritt \& Cummins, 1984). Segundo Merritt \& Cummins (1996), os quironomídeos da subfamília Orthocladiinae são encontrados principalmente em ambientes lóticos. Sanseverino et al. (1998), trabalhando 
em diferentes biótopos aquáticos na Serra do Subaio (Rio de Janeiro), verificaram que os Orthocladiinae estiveram associados principalmente a áreas de correnteza.

Segundo Boulton et al. (1988), o gênero Rheotanytarsus é comum na superfície de rochas, escondendo-se em suas casas feitas de material particulado fino. O gênero Rheotanytarsus, contrutor de tubo fixo e coletorfiltrador característico, foi encontrado em cachoeiras e no substrato rochoso por Sanseverino et al. (1998). No Córrego Itaúna, este gênero também foi abundante em rochas junto com o gênero Cricotopus, mas também foi encontrado em substrato vegetal (de corredeira e poção).

Segundo Sanseverino et al. (1998), Corynoneura foi o grupo dominante em "litter" de correnteza, sendo também encontrado em "litter" de depósito e associado a macrófitas aquáticas. O mesmo padrão foi verificado no substrato vegetal do Córrego Itaúna, sendo este gênero predominante em "litter" de corredeiras. O gênero Polypedilum é comum no sedimento, umas poucas espécies são encontradas em substratos rochosos ou em plantas aquáticas (Wiederholm, 1983). No Córrego Itaúna, o gênero Polypedilum também teve a maior abundância no sedimento.

Verificamos, portanto através deste trabalho a maior densidade de macroinvertebrados no substrato rochoso (de maior estabilidade), a maior riqueza no substrato vegetal (o qual apresenta múltiplas funções) e a predominância de insetos em todos os substratos, com destaque para a subfamília Orthocladiinae (família Chironomidae, Ordem Diptera), citada na literatura como um grupo de ocorrência comum em ambientes lóticos.

\section{Agradecimentos}

Os autores agradecem: a Hamilton Antônio Rodrigues pelo auxílio no trabalho de campo; à Carolina Minte Vera e Luis Maurício Bini pelos auxílios estatísticos; a Tatiana Chrysostoma Santos e Rosalys Guahyba (Museu Nacional do RJ) pela checagem dos invertebrados da Ordem Odonata e Trichoptera, respectivamente; a Sérgio Vanin pela checagem dos invertebrados da Ordem Coleoptera; a Gisela Shimizu, pela amizade, incentivo e apoio. 


\section{Referências Bibliográficas}

Allan, J.D., 1995. Stream ecology. Structure and function of running waters. Chapman \& Hall, London. 388 p.

Belle, J., 1992. Studies on ultimate instar larvae of neotropical Gomphidae, with the description of Tibiagomphus gen. nov. (Anisoptera). Odonatologica 21:1-24.

Borror, D.J. \& Delong, D.M., 1969. Introdução ao estudo dos insetos. São Paulo, Edgard Blücher. 653 p.

Boulton, A.J.; Spangaro, G.M. \& Lake, P.S., 1988. Macroinvertebrate distribution and recolonization on stones subjected to varying degrees of disturbance: an experimental approach. Arch. Hydrobiol.. 113:551-576.

Brennan, A.; Mclachlan, A.J. \& Wotton, R.S., 1978. Particulate material and midge larvae (Chironomidae: Diptera) in an upland river. Hydrobiologia 59:67-73.

Brown, A.V. \& Brussock, P.P., 1991. Comparison of benthic invertebrates between riffles and pools. Hydrobiologia. 220:99-108.

Carvalho, A.L., 1989. Description of the larva of Neuraeschna costalis (Burmeister), with notes on its biology, and a key to the genera of Brasilian Aeshnidae larvae (Anisoptera). Odonatologica. 18:325-332.

Costa, C.; Vanin, S.A. \& Casari-Chen, S.A., 1988. Larvas de Coleoptera do Brasil. Museu de Zoologia da Universidade de São Paulo, São Paulo. 282 p.

Cressa, C., 1994. Structural changes of the macroinvertebrate community in a tropical river. Verh. Internat. Verein. Limnol. 25:1853-1855.

Dobson, M., 1994. Microhabitat as a determinant of diversity: stream invertebrates colonizing leaf packs. Freshwater Biol. 32:565-572. 
Doeg, T.J.; Marchant, R.; Douglas, M. \& Lake, P.S., 1989. Experimental colonization of sand, gravel and stones by macroinvertebrates in the Acheron River, southeastern Australia. Freshwater Biol. 22:57-64.

Egglishaw, H.J., 1964. The distributional relationship between the botton fauna and plant detritus in streams. J. Anim. Ecol. 33:463-476.

Epler, J.H., 1992. Identification manual for the larval Chironomidae (Diptera) of Florida. Department of environmental Regulation, Tallahasse-Florida.

Froehlich, C., 1966. Studies on Brasilian Plecoptera 1. Some Gripopterygidae From the Biological Station at Paranapiacaba, State of Sao Paulo. Beitr. Z. Neotrop. Fauna. 6:17-39.

Gurtz, M.E. \& Wallace, J.B., 1984. Substrate - mediated response of stream invertebrates to disturbance. Ecology 65:1556-1569.

Hawkins, C.P.; Murphy, M.L.; Anderson, N.H. \& Wilzbach, M.A., 1983. Density of fish and salamanders in relation to riparian canopy and physical habitat in streams of the northwestern United States. Can. J. Fish. Aquat. Sci. 40:1173-1185.

Hynes, H.B.N., 1970. The ecology of running waters. $3^{\mathrm{a}}$ ed, Canada, Toronto Press. 555 p.

Kikuchi, R.M. \& Uieda. V.S., 1998. Composição da comunidade de invertebrados de um ambiente lótico tropical e sua variação espacial e temporal. p. 157-173. In: Ecologia de Insetos Aquáticos. Nessimian, J.L. \& A.L. Carvalho. E. (eds). Series Oecologia Brasiliensis, vol. V. PPGE-UFRJ. Rio de Janeiro, Brasil.

Lenat, D.R.; Penrose, D.L. \& Eagleson, K.W., 1981. Variable effects of sediment addition on stream benthos. Hydrobiol. 79:187-194.

Lopretto, E.C. \& Tell, G., 1995. Ecosistemas de águas continentales. Metodologias para su estudio. Ediciones Sur. 
Mackay, R.J. \& Kalff, J., 1969. Seasonal variation in standing crop and species diversity of insects communities in a small Quebec stream. Ecology. 50:101-108.

Mason Jr., W.T., 1973. An introdution to the identification of Chironomid Larvae. Analytical Quality Control Laboratory, National Environmental Research Center, U.S. Environmental Protection Agency, Cincinnati, Ohio, $90 \mathrm{p}$.

Merritt, R.W. \& Cummins, K.W., 1984. An introdution to the aquatic insects of North America. $2^{\mathrm{a}}$ ed., Dubuque, Kendall/Hunt. $722 \mathrm{p}$.

Merritt, R.W. \& Cummins, K.W., 1966. An introdution to the aquatic insects of North America. $3^{\mathrm{a}}$ ed., Dubuque, Kendall/Hunt. 862 p.

Minshall, G.W. \& Minshall, J.N., 1977. Microdistribution of benthic invertebrates in a Rocky Mountain (U.S.A.) stream. Hydrobiologia 55:231-249.

Neves, R.J., 1979. Secondary production of epilithic fauna in a woodland stream. The American Midland Naturalist 102:209-224.

Oliver, D.R.; Mcclymont, D. \& Roussel, M.E., 1978. A key to some larvae of Chironomidae (Diptera) from the Mackenzie and Propine River watersheds. Fisheries and Marine Service Technical Report no791, Manitoba, Canada. 72 p.

Oliveira, L.G., 1991. Estudo da fauna de Trichoptera do Córrego do Pedregulho - Pedregulho, SP, com especial referência a Família Hidropsychidae. (Dissertação de Mestrado) - Departamento de Biologia, Faculdade de Filosofia, Ciências e Letras, Universidade de São Paulo, Ribeirão Preto-SP. 84 p.

Ormerod, S.J., 1988. The micro-distribution of aquatic macroinvertebrates in the Wye river system: the result of abiotic or biotic factors?. Freshwater Biol. 20: 241-247. 
Payne, J. 1986. The ecology of tropical lakes and rivers. John Wiley \& Sons, Chicheter.

Pennak, R.W., 1978. Freshwater invertebrates of the United States. $2^{\mathrm{a} e d .}$., Jonh Wiley \& Sons, New York. 803 p.

Pennak, R.W., 1989. Freshwater invertebrates of the United States. Protozoa to Mollusca. $3^{a}$ ed., Jonh Wiley \& Sons, New York. 628 p.

Pérez, G.R., 1988. Guía para el estudio de los macroinvertebrados acuáticos del Departamento de Antioquia, Colombia, Bogotá. Editorial Presencia Ltda. 217 p.

Reid, R.A., Somers, K.M. \& David, S.M., 1995. Spatial and temporal variation in littoral-zone benthic invertebrates from three south-central Ontario lakes. Can. J. Fish. Aquat. Sci. 52:1406-1420.

Resh, V.H. \& Rosenberg, D.M., 1984. The ecology of aquatic insects. $1^{\text {a }}$ ed., New York, Praeger Publishers. 625 p.

Sanseverino, A.M., Nessimian, J.L. \& Oliveira, A.L.H., 1998. A fauna de Chironomidae (Diptera) em diferentes biótopos aquáticos na Serra do Subaio (Teresópolis, RJ). Pp. 157-173. In: Ecologia de Insetos Aquáticos. Nessimian, J.L. \& A.L. Carvalho. E. (eds). Series Oecologia Brasiliensis, vol. V. PPGE-UFRJ. Rio de Janeiro, Brasil.

Stehr, F.W., 1987. Immature Insects. Vol.1. Kendall/Hunt Publishing Company. 754 p.

Scullion, J.; Parish, C.A.; Morgan, N. \& Edwards, R.W., 1982. Comparison of benthic macroinvertebrate fauna and substratum compositon in riffles and pools in the impounded River Elan and the unreguladed River Wye, mid-Wales. Freshwat. Biol. 12:579-595.

Short, R.A.; Canton, S.P. \& Ward, J.V., 1980. Detrital processing and associated macroinvertebrates in a Colorado mountain stream. Ecolog. 61:727-732. 
Statzner, B., 1981. The relation between "hydraulic stress" and microdistribution of benthic macroinvertebrates in a lowland running water system, the Schierenseebrooks (North Germany). Arch. Hydrobiol. 92:192-218.

Statzner, B. \& Higler, B., 1986. Stream hydraulic as a major determinant of benthic invertebrate zonation patters. Freshwater Biol. 16:127-139.

Ter Braak, C.J.F., 1995. Ordination. pp. 91-113. In: Data analysis in community and landscape ecology. Jongman, R.H.G.; Ter Braak, J.F. \& Van Tongeren, O.F.R. (eds), University press, Cambridge.

Ter Braak, C.J.F. \& Prentice, I.C., 1988. A theory of gradient analysis. Adv. Ecol. Res. 18: 272-330.

Tikkanen, P.; Laasonen, P.; Muotka, T.; Huhta, A. \& Kuusela, K., 1994. Shortterm recovery of benthos following disturbance from stream habitat rehabilitation. Hydrobiol. 273:121-130.

Trivinho-Strixino, S. \& Strixino, G., 1991. Duas novas espécies de Nimbocera Reiss (Diptera, Chironomidae) do Estado de São Paulo, Brasil. Rev. Bras. Entomol. 33:173-178.

Trivinho-Strixino, S. \& Strixino, G., 1995. Larvas de Chironomidae (Diptera) do Estado de São Paulo: Guia de identificação e diagnoses dos gêneros. São Carlos:PPG-ERN/UFSCAR. 299 p.

Walker, I., 1986. Sobre a ecologia e biologia da decomposição da matéria orgânica em águas amazônicas. Acta Limnol. Bras. 1:557-573.

Walker, I., 1988. Study of benthic micro-faunal colonization of submerged litter leaves in the central Amazonian blackwater stream Tarumã-Mirim (Tarumanzinho). Acta Limnol. Bras. 2:623-648.

Walker, I., 1994. The benthic litter-dwelling macrofauna of the Amazonian forest stream Tarumã-Mirim: patterns of colonization and their implications for community stability. Hydrobiol. 291:75-92. 
Wallace, J.B.; Gurtz, M.E. \& Smith-Cuffney, F., 1988. Long-term comparisons of insect abundances in disturbed and undisturbed Appalachian headwater streams. Verh. Internat. Verein. Limnol. 23:1224-1231.

Wiederholm, T., 1983. Chironomidae of the Holartic region - Keys and diagnoses (Part 1 - Larvae). Entomol. Scand. Suppl. 19:1-457.

Wiley, M.J. \& Kohler, S.L., 1981. An assessment of biological interations in a epilithic stream community using time-lapse cinematography. Hydrobiol. 78:183-188.

Wise, D.H. \& Molles, M.C.Jr., 1979. Colonization of artificial substrates by stream insects: influence of substrate size and diversity. Hydrobiol. 65:69-74.

Wright J.F.; Moss, D.; Armitage, P.D. \& Furse, M.T., 1984. A preliminary classification of running-water sites in Great Britain based on macroinvertebrate species and the prediction of community type using environmental data. Freshwater Biol. 14:221-256. 